\title{
O SALÁRIO DE RESERVA E A OFERTA DE TRABALHO: EVIDÊNCIAS PARA O BRASIL
}

\author{
Paulo Aguiar do Monte * \\ Hilton Martins de Brito Ramalho ${ }^{\dagger}$ \\ Márcia de Lima Pereira $\ddagger$
}

\begin{abstract}
Resumo
O objetivo desse artigo é estimar o salário de reserva dos trabalhadores ocupados, desocupados e inativos no Brasil. Para tanto, a partir dos dados da PNAD de 2006, foi estimado um modelo de determinação conjunta da oferta de trabalho, emprego e salários, considerando a correção de viés de seleção amostral envolvida nas decisões de participação no mercado de trabalho e de procura por emprego. Em seguida, os salários de reserva foram calculados descontando-se a utilidade atrelada à participação na forca de trabalho das estimativas de salários preditos, condicionadas ao modelo supracitado. Em geral, as evidências encontradas sugerem uma relação positiva do salário de reserva com o nível de escolaridade e faixa etária dos trabalhadores.
\end{abstract}

Palavras-chave: Salário de Reserva, Auto seleção, Oferta de Trabalho, Brasil.

\begin{abstract}
The main goal of this paper is to estimate the reservation wage either for employed, unemployed or economically inactive individuals in Brazil. For this purpose, we use data from the National Household Sample Survey (PNAD) from 2006 and estimate a model of joint determination of labor supply, employment and wages, taking into account a correction of sample selection bias involved in both the workforce participation decision and the job search process. In turn, the reservation wages were estimated by discounting the value of utility for the workforce participation decision from the linear predictions of conditional wages. The finding suggests a positive relationship between reservation wages, education level and aged of workers from different positions on the labor market.
\end{abstract}

Keywords: Reservation Wage, Self-selection, Labor Supply, Brazil JEL classification: J30, J31

\footnotetext{
* Departamento de Economia - UFPB. E-mail:pauloaguiardomonte@gmail.com.

† Departamento de Economia - UFPB. E-mail:hiltonmbr@gmail.com.

‡ Departamento de Economia - UFCG. E-mail:marcialpbr@yahoo.com.
} 


\section{Introdução}

Uma questão central na discussão acerca dos determinantes da oferta de mão de obra é o fator salarial. A ênfase dada pela Teoria Neoclássica já chamava atenção para o papel do diferencial entre o salário de mercado e o salário de reserva na escolha individual entre trabalho e lazer. Nesse contexto, o salário de reserva, ao contrário do salário determinado pelo mercado de trabalho, possui caráter subjetivo, ou seja, é compreendido como nível de remuneração limiar, a partir do qual o trabalhador aceita ou não se inserir em determinada ocupação (Cahuc \& Zylberberg 2004, Mohanty 2005, Pannenberg 2007). A partir das proposições neoclássicas, emergem, nos anos 50 , as suposições inerentes a Teoria do Capital Humano, segundo a qual, os investimentos realizados pelos indivíduos em educação/qualificação ampliam a capacidade produtiva destes, fazendo surgir uma diferenciação entre os trabalhadores, e, por conseguinte, diferentes dotações salariais e exigências subjetivas quanto à oferta individual de trabalho.

A maior parte dos estudos empíricos sobre salário de reserva, contudo, baseia-se na Teoria da Procura por Emprego (Job Search), cujos expoentes são McCall (1970) e Mortensen (1970). Esses autores relaxam a hipótese de informação perfeita, presente nos modelos neoclássicos de mercado de trabalho competitivo. Assumem que as informações sobre a localização dos postos de trabalho são incompletas e que existem custos para obtenção das mesmas. Essas condições implicam formação de expectativas quanto aos rendimentos futuros e determinação de um salário de reserva por parte dos indivíduos.

Por outro lado, de acordo com Mohanty (2005), o salário de reserva depende da possibilidade de os indivíduos receberem uma oferta salarial, a qual, por sua vez, é condicionada à situação do mercado de trabalho e à qualificação/educação dos indivíduos. Neste contexto, o estudo do salário de reserva se constitui uma investigação do comportamento de indivíduos na busca por uma colocação, denotando preferências e expectativas acerca de melhores propostas de emprego, maiores rendimentos e melhor bem estar. Portanto, para o autor em destaque, faz-se necessário a determinação de salários de reserva para indivíduos ocupados, desocupados e os inativos ${ }^{1}$.

Já Peralta (2005), argumenta que é necessário conhecer o salário de reserva dos trabalhadores ocupados, uma vez que os mesmos buscam, constantemente, melhores oportunidades de emprego e salários. Assim, o salário que consideram compatível com suas habilidades e características nem sempre será aquele que auferido na ocupação atual, de maneira que as variáveis que influenciam as preferências de trabalhadores e empregadores, no mercado de trabalho, são as mesmas que afetam o salário de mercado e o salário de reserva.

No Brasil, são raros os estudos empíricos a respeito da influência do salário de reserva na oferta de mão de obra. Oliveira \& Carvalho (2006), por exemplo, utilizam dados da Pesquisa de Padrão de Vida (PPV), que apresenta, explicitamente, informações acerca do salário de reserva fornecido pelos indivíduos pesquisados. Já Menezes et al. (2005), com base na Pesquisa de Emprego e Desemprego (PED), usaram como proxy do salário de reserva, o salário médio re-

\footnotetext{
${ }^{1}$ Hofler \& Murphy (1994), por exemplo, estimaram o salário de reserva através da técnica de regressão estocástica para os trabalhadores ocupados, tendo como base a Teoria da Procura por Emprego, e encontraram que o salário do trabalhador é 25\% maior do que o seu salário de reserva, valores estes que diferem conforme o perfil socioeconômico dos trabalhadores.
} 
cebido pelos trabalhadores ocupados. No que tange à literatura internacional, existem diversos estudos efetuados, a saber: Jones (1988), Blau (1991), Hofler \& Murphy (1994), Hinnosaar (2004), Mohanty (2005), Pannenberg (2007) que, de forma resumida, explicitam a relação de determinação existente entre algumas variáveis socioeconômicas dos indivíduos e o salário de reserva; este, na maioria das vezes, já informado por meio das pesquisas existentes nos respectivos países.

Nesse contexto, o principal objetivo do presente estudo é estimar, empiricamente, o salário de reserva dos indivíduos ocupados, desocupados e inativos no Brasil. Para atingir tal objetivo, foram usados dados da Pesquisa Nacional por Amostras de Domicílio (PNAD) de 2006 e um modelo de determinação conjunta de oferta de trabalho, emprego e salários, considerando a correção de viés de seleção amostral envolvido nas decisões de oferta de trabalho e de procura por emprego (Tunali 1986). Em seguida, os salários de reserva foram calculados descontando-se a utilidade atrelada à participação na forca de trabalho das estimativas de salários preditos, condicionadas ao referido modelo e conforme proposto por Mohanty (2005).

Além desta seção introdutória, este artigo está dividido em mais cinco partes. A segunda seção apresenta uma breve revisão teórica relacionada ao salário de reserva. A terceira seção é dedicada à apresentação dos procedimentos metodológicos adotados. Na quarta seção, apresenta-se uma análise descritiva dos indivíduos inseridos na amostra. Na seção cinco, são analisados os resultados referentes à probabilidade de participação/contratação e aos salários de reserva, estimados para as três condições na atividade: ocupados, desocupados e inativos. Por fim, a última seção destina-se às considerações finais.

\section{Discussão acerca do salário de reserva}

\subsection{Abordagem conceitual}

Tomando, como ponto de partida, o comportamento do trabalhador e suas relações sociais no mercado de trabalho, é factível supor que este busca uma ocupação que lhe proporcione um rendimento considerado compatível ao trabalho desempenhado, às suas características pessoais e ao investimento que realizou em educação/qualificação (capital humano). Nesse sentido, é possível introduzir algumas formas conceituais para o salário de reserva. De acordo com Cahuc \& Zylberberg (2004), o salário de reserva se constitui em um patamar salarial no qual o trabalhador é indiferente entre trabalhar e continuar procurando um emprego. Já para Pannenberg (2007), o salário de reserva apresenta todas as informações sobre o comportamento de procura por trabalho, e é um mecanismo pelo qual um trabalhador aceita salários ofertados e cessa a procura por um trabalho. Mohanty (2005), por sua vez, amplia o conceito de salário de reserva, acrescentando, além dos trabalhadores empregados e desempregados, os inativos, ao definir essa variável como o salário mínimo necessário que leva um trabalhador a ingressar no mercado.

A ideia central explicitada nos diversos conceitos de salário de reserva parece ter ligação direta com as proposições teórico-econômicas defendidas por Smith (1996), ao retratar na sua Teoria dos Salários de Subsistência, onde este se constitui um valor abaixo do qual parece ser impossível, em determinado período, reduzir os salários, mesmo para os trabalhadores menos qualifica- 
dos. David Ricardo ${ }^{2}$ prossegue com a proposição de salários de subsistência de Adam Smith, mas utiliza uma terminologia diferente, isto é, a de preço natural do trabalho. Nesse enfoque, o salario de reserva é uma espécie de rendimento necessário para permitir que os trabalhadores se substituam e perpetuem sua raça. Ricardo também apresenta o conceito de preço de mercado, o qual, através das oscilações entre oferta e demanda, pode ser superior ou inferior ao preço natural. Assim, de acordo com Ricardo (2006), se o preço de mercado excede o preço natural, o trabalhador encontra-se em condição próspera e feliz, desfrutando de grande quantidade de bens de primeira necessidade e do que ele chama de prazeres da vida, apresentando forte similaridade com as proposições atuais acerca do salário de reserva. Assim, verifica-se que o conceito de salário de reserva apresenta raízes históricas desde o marco da Economia enquanto ciência, até chegar às proposições explicitadas pela Teoria Neoclássica e as demais teorias do mercado de trabalho, que apresentam o conceito sob uma nova estrutura de funcionamento.

\subsection{A Teoria Neoclássica da Oferta de Mão de Obra e a Teoria da Procura por Emprego}

A Teoria Neoclássica sugere que a relação entre salário de mercado e salário de reserva é decisiva no processo de escolha individual entre trabalho e lazer. Nesse contexto, o salário de reserva seria compreendido como um valor limiar (subjetivo), a partir do qual o trabalhador aceita determinada ocupação. Caso o salário de mercado $\left(w^{m}\right)$ exceda o salário de reserva $\left(w^{r}\right)$, o indivíduo decide participar ativamente do mercado de trabalho e ofertar um número positivo de horas de trabalho $(h>0)$; caso contrário, todo o seu tempo será dedicado ao lazer. Formalmente:

$$
\begin{aligned}
& h>0 \leftrightarrow w^{m}>w^{r} \\
& h=0 \leftrightarrow w^{m} \leq w^{r}
\end{aligned}
$$

Assim, quanto maior o valor que o indivíduo atribui ao lazer, ou considerando a influência de outras variáveis, como o montante das rendas do não trabalho ou a sua capacidade produtiva, maior será o seu salário de reserva (Rogerson et al. 2005). Nestes termos, verifica-se que a Teoria Neoclássica não considera a possibilidade de diferenciais salariais, ao assumir que a mão de obra é homogênea.

Todavia, a partir dos anos 50, surge a Teoria do Capital Humano ${ }^{3}$, que busca demonstrar a existência de diferenciais de salários, assumindo a hipótese de heterogeneidade dos trabalhadores. Nessa abordagem, a ênfase recai sobre a educação e o treinamento, que são entendidos como investimento em capacidades e conhecimentos. Logo, as diferenças salariais são atribuídas às discrepâncias em termos de investimento em capital humano. A decisão individual de investir em capital humano, por seu turno, baseia-se nos custos realizados para obtenção de maior escolaridade em relação aos rendimentos estimados após o período adicional de estudo. Portanto, o salário de reserva possui forte relação com o capital humano adquirido, sobretudo, em relação ao nível educacional e à experiência obtida em ocupações anteriores. Mohanty

\footnotetext{
${ }^{2}$ Economista inglês (1772-1823) expõe suas principais teses na obra "Princípios de Economia Política e Tributação".

${ }^{3}$ Essa corrente teórica tem como precursores artigos seminais de Becker (1962), Schultz (1961) e Mincer (1958).
} 
(2005), por exemplo, mostra que, quanto maior o nível educacional dos trabalhadores, maior a rentabilidade esperada.

Adicionalmente, a partir da década de 1970, surgem as proposições da chamada Teoria da Procura por Emprego (Job Search Theory), a qual dá continuidade ao processo de ruptura de alguns pressupostos da Teoria Neoclássica, tornando-se uma das principais ferramentas teóricas e empíricas para compreender o funcionamento do mercado de trabalho. Nessa nova concepção teórica, há a possibilidade de existência de desemprego involuntário e as informações, acerca de ofertas de empregos e salários pagos, são imperfeitas no mercado de trabalho. Mais especificamente, os indivíduos não possuem informação simétrica e completa, portanto, a obtenção de elementos informativos adicionais não se verifica sem a geração de custos.

Nesse sentido, a Teoria da Procura por Emprego busca explicar uma nova idealização da dinâmica do mercado de trabalho, apresentando, como objetivo principal, o comportamento dos trabalhadores desempregados e empregadores em um mercado equilibrado mesmo com a existência de desemprego. Adicionalmente, afirma-se que a busca por uma ocupação ocorre com o objetivo maior de maximizar a utilidade por meio de escolhas ótimas, como a intensidade na qual o trabalhador realiza a atividade de procura e a determinação de um salário de reserva. Assim, considerando o salário oferecido pelo mercado, caso este seja superior ao salário de reserva, o indivíduo aceita esta oferta e se insere na ocupação; caso contrário, o indivíduo prossegue com a busca por outro trabalho que lhe proporcione maior utilidade, em termos de salários mais elevados.

O conceito de salário de reserva, advindo da Teoria Neoclássica, ganha uma importância maior na Teoria da Procura por Emprego (Job Search Theory). Dado que os indivíduos mais qualificados possuem um salário reserva mais elevado, justamente para recuperar todos os investimentos feitos em capital humano ao longo de sua vida, as ofertas de emprego e remunerações oferecidas teriam uma distribuição específica para cada indivíduo, dependendo, principalmente, de seus atributos pessoais ${ }^{4}$.

As análises metodológicas dos modelos da Teoria da Procura por Emprego levam em conta a dimensão temporal, onde a duração no desemprego interfere na decisão do indivíduo procurar um emprego e no esforço da procura, afetando assim a oferta de trabalho. Logo, o indivíduo que está à procura de um emprego deve agir de forma estratégica, pois, parte de seus atributos, como o nível de escolaridade, pode usado como "filtro" para conseguir um emprego, visto que, em geral, os anos de estudos são tomados pela firma como um indicador de potencial produtividade, tornando-se um dos critérios utilizados, pelas firmas, para a seleção dos trabalhadores.

Tendo como base uma das proposições da Teoria da Procura por Emprego que relaciona o salário oferecido no mercado $\left(w^{m}\right)$ e o salário de reserva $\left(w^{r}\right)$, pode-se inferir a respeito da determinação do tempo ótimo de busca pelo emprego. De forma resumida, os modelos Job Search supõem que, se $w^{m}>w^{r}$, o indivíduo aceita a oferta de trabalho e se insere na ocupação. No entanto, ao contrário do que é proposto na Teoria Neoclássica, na Teoria da Procura

\footnotetext{
${ }^{4} \mathrm{O}$ salário de reserva também é influenciado pelas condições do mercado de trabalho, tais como a taxa de desemprego e as rendas do não trabalho (exemplo: os chamados benefícios de desemprego), que tendem a alterar o custo de oportunidade da procura de emprego e a intensidade de procura, modificando, assim, o salário de reserva do indivíduo. Para maiores detalhes ver Bloemen (1997).
} 
por Emprego, caso o salário de mercado seja inferior ao salário de reserva $\left(w^{m}<w^{r}\right)$, o indivíduo não faz opção exclusivamente pelo lazer, mas prossegue com a busca por outro trabalho que lhe proporcione maior utilidade. Assim, o salário de reserva, de acordo com Fitzgerald (1998), pode ser representado pela equação abaixo:

$$
w_{t}^{r}=w^{u}+\phi\left(w_{t-1}^{r}\right)
$$

Onde, o lado esquerdo da equação (3) pode ser considerado como o benefício de aceitar uma oferta de salário ao preço do salário de reserva $\left(w_{t}^{r}\right)$ no período $t$. Já o lado direito, pode ser considerado como o valor de rejeitar uma oferta de emprego, que inclui o valor do benefício do desemprego $\left(w^{u}\right)$ mais a expectativa de receber uma nova oferta de emprego em um período posterior. Assim, $\phi$ representa uma função redutora do salário de reserva visto que quanto mais tempo o trabalhador permanecer desempregado menor a chance de receber uma proposta compatível ao seu salário de reserva inicial $\left(w_{t-1}^{r}\right)$.

Segundo Fitzgerald (1998), quanto maior a probabilidade de o trabalhador receber uma proposta satisfatória de emprego, mais elevado será o seu salário de reserva, salvaguardada sua dependência em relação às características pessoais/regionais. Ademais, é de se esperar que o indivíduo que procura um emprego tenha preferência por ocupações cujos rendimentos (salários) sejam mais elevados, já que, agindo racionalmente, ele pretende reduzir sua atividade no mercado ao passar do tempo e destinar mais tempo ao lazer (não trabalho). Entretanto, o mesmo sabe que a probabilidade de encontrar uma ocupação que lhe pague um salário elevado depende dos seus atributos pessoais e da sua procura pelo emprego. Como afirma Hinnosaar (2004), desde que esta busca não implique em custos adicionais, o indivíduo continuará procurando até encontrar uma melhor proposta de emprego. Apesar do tempo maior de procura estar relacionado a chances maiores de encontrar um emprego com melhor salário, geralmente, o maior tempo também se relaciona positivamente com o custo incorrido nesta busca ${ }^{5}$. Logo, a Teoria da Procura por Emprego ressalta que os indivíduos deveriam disponibilizar um tempo ótimo de procura de acordo com a intensidade de procura e com o seu salário de reserva.

\section{Estratégia Empírica}

Tendo em vista a obtenção de evidências acerca do salário de reserva e de seu papel na determinação da oferta individual de trabalho, a análise empírica desse artigo é fundamentada no modelo estrutural de determinação conjunta da participação, emprego e salários, considerando amostra de não aleatória de trabalhadores (Tunali 1986). Por sua vez, a estimativa dos salários de reserva é feita de forma indireta, a partir da diferença entre os salários preditos e a função de preferência dos indivíduos no mercado de trabalho, conforme empregado por Mohanty (2005).

De acordo com a literatura referente ao tema, a determinação da participação dos indivíduos no mercado de trabalho estaria condicionada por um

\footnotetext{
${ }^{5}$ Para Whipple (1973) a distribuição da oferta de trabalho é dependente do esforço particular do indivíduo pela procura do emprego e dos seus atributos. Segundo o autor, se um indivíduo não se considera qualificado para determinado tipo de trabalho, ele não irá procurar este tipo de emprego, e, consequentemente, haverá uma baixa probabilidade de tal emprego ser oferecido a este indivíduo.
} 
conjunto de características socioeconômicas observáveis e de capital humano, a saber: gênero, faixa etária, nível de escolaridade, localização regional, raça, outras fontes de rendimentos, condição na família; assim como, dependeria de características produtivas não diretamente observáveis, que influenciariam na autosseleção dos indivíduos entre as populações economicamente ativa/inativa. Por outro lado, o empregador também considera os atributos pessoais e qualidades não observadas do trabalhador no processo de sua contratação ${ }^{6}$. As características não observadas como motivação, persistência e entusiasmo, também afetariam a probabilidade de o indivíduo economicamente ativo ser contratado, uma vez que, ele pode levar vantagem em relação a outros trabalhadores no processo de procura por emprego em um ambiente de informação assimétrica.

Os determinantes das probabilidades conjuntas de participação/contratação dos indivíduos no mercado de trabalho podem ser modelados, empiricamente, a partir de um sistema probit bivariado. Tal modelo considera que as decisões de participação/não participação no mercado e de contratação/não contratação ocorrem simultaneamente. A despeito de esta característica ser pouco realista, visto que, intuitivamente, tais decisões devem proceder de forma sequencial, isto é, inicialmente o indivíduo decide entre ofertar ou não sua força de trabalho e, em seguida, gasta certo período de tempo procurando emprego até uma possível contratação ou não; o modelo apresenta vantagens operacionais atraentes, dentre as quais:

i) evita a hipótese da independência das alternativas irrelevantes, sob a qual as razões de probabilidades não se alterariam mediante uma alteração no conjunto de escolhas, o que é corriqueiro nos modelos do tipo logit multinomial/condicional/aninhado;

ii) em comparação a um probit ordenado, tem a peculiaridade de superar potenciais problemas de endogeneidade decorrentes da aquisição de um novo conjunto de informações ao longo de um processo de escolha sequencial.

E, dentre as possíveis limitações do método, destaca-se que elas são decorrentes do fato de que os salários de mercado, para os indivíduos desocupados e inativos, são baseados em um processo comparativo entre as características destes e dos trabalhadores que se encontram ocupados, cujos resultados obtidos poderiam não corresponder exatamente àqueles salários obtidos caso estivessem efetivamente ocupados, embora este possa ser considerado um bom exercício para tal análise.

Dada a discussão anterior, a seguir apresenta-se com maior detalhamento a estratégia empírica.

\subsection{Modelo Empírico}

Considere-se o seguinte sistema probit bivariado de seleção amostral:

$$
y_{1}^{*}=\theta_{1} z_{1}+u_{1} \quad \therefore\left\{\begin{array}{l}
y_{1}=1 \leftrightarrow y_{1}^{*}>0 \\
y_{1}=0 \leftrightarrow y_{1}^{*} \leq 0
\end{array}\right.
$$

\footnotetext{
${ }^{6}$ Supõe-se um ambiente de informação perfeita, isto é, completa e simétrica.
} 


$$
y_{2}^{*}=\theta_{2} z_{2}+u_{2} \quad \therefore \quad\left\{\begin{array}{l}
y_{2}=1 \leftrightarrow y_{2}^{*}>0 \\
y_{2}=0 \leftrightarrow y_{2}^{*} \leq 0
\end{array}\right.
$$

Onde: $\theta_{1}$ e $\theta_{2}$ são vetores de parâmetros; $z_{1}$ e $z_{2}$ vetores que contém variáveis de atributos pessoais e de capital humano para o controle dos custos associados à participação no mercado de trabalho e à procura por emprego; $u_{1}$ e $u_{2}$ são termos aleatórios que representam a heterogeneidade não observada e com coeficiente de correlação $\rho \equiv \operatorname{corr}\left(u_{1}, u_{2}\right)$.

O primeiro índice de seleção $y_{1}^{*}$ (equação 4), ordena as preferências dos indivíduos em relação a oferta de mão de obra, e, portanto, a depender do sinal do índice, o indivíduo típico decide participar ou não da oferta no mercado de trabalho. Assim, a variável binária $y_{1}$ assume o valor 1 quando o indivíduo opta por ser economicamente ativo e 0 caso contrário. Já a equação (5) gera o índice de utilidade $y_{2}^{*}$, que representa as preferências dos empregadores quanto à contratação ou não dos ofertantes de trabalho. Quando o trabalhador está empregado, a variável dummy $y_{2}$ recebe o valor 1 e 0 quando o mesmo estiver desempregado. Quanto ao coeficiente de correlação $\rho$, um valor $\rho \neq 0$ e estatisticamente significativo, informa que as decisões de participação e contratação são interdependentes e consistentes com o modelo adotado, ou seja, atributos não observados que influenciam a decisão de participação no mercado de trabalho estariam correlacionados com outros atributos determinantes da empregabilidade do trabalhador ${ }^{7}$.

A decisão de oferta individual de trabalho é fundamentada no processo de maximização de utilidade, onde é feita uma comparação entre o salário de mercado e o salário de reserva. Caso o primeiro supere o segundo, a função de preferência pela participação no mercado de trabalho atesta uma utilidade positiva $y_{1}^{*}>0$, e o indivíduo opta por ofertar mão de obra.

O modelo estrutural pode ser completado adicionando-se uma equação de salários do tipo minceriana para os trabalhadores participantes e empregados no mercado de trabalho:

$$
\ln W_{3}=\beta_{3} X_{3}+\varepsilon_{3} \leftrightarrow\left(y_{1}=y_{2}=1\right)
$$

Onde: $\beta_{3}$ é um vetor de parâmetros; $X_{3}$ um vetor de características pessoais que afetam a determinação do salário de mercado para o indivíduo e $\varepsilon_{3}$ um termo estocástico correlacionado com as equações de seleção (4) e (5). Vale ressaltar dois pontos fundamentais. Primeiro, omitiu-se duas equações de salários do modelo estrutural, pois a censura na amostra não permite observar os salários de mercado para os participantes e desocupados $\left(y_{1}=1 ; y_{2}=0\right)$ e inativos $\left(y_{1}=0\right)$. Em segundo lugar, a estimação de (6) isoladamente, por Mínimos Quadrados Ordinários (MQO), resultaria em estimadores tendenciosos devido à presença de seletividade dos indivíduos na amostra (Heckman 1979).

As equações (4), (5) e (6) formam a especificação empírica do modelo de determinação conjunta de participação, emprego e salários no mercado de

\footnotetext{
${ }^{7}$ Ainda é importante enfatizar a presença de censura no processo de autosseleção dos indivíduos na amostra. Isso fica evidente, ao considerar-se a seguinte condição de observância: o indivíduo é empregado ou desempregado apenas se é economicamente ativo, ou seja, $y_{2}$ apenas é observado se $y_{1}=1$. Logo, não há como observar, simultaneamente, na amostra, um indivíduo empregado e inativo.
} 
trabalho (endogenous switching regression). Para obter estimadores não tendenciosos na equação de rendimentos, Tunali (1986) faz uma extensão dos métodos de Lee (1978) e Heckman (1979), propondo a estimação do modelo em dois estágios. Assumindo-se que os termos de erros das referidas equações seguem uma distribuição normal multivariada, com médias zero e matriz de covariância positivamente definida, o probit bivariado (4)-(5) deve ser estimado em primeiro estágio, o que permite computar, a partir das probabilidades preditas, os seguintes termos de controle da heterogeneidade não observada para inativos, desocupados e empregados: $\lambda_{1}=f\left(C_{1}\right) /\left[1-F\left(C_{1}\right)\right]$, $\lambda_{21}=f\left(C_{1}\right) F\left(-C_{2}^{*}\right) / G\left(C_{1},-C_{2},-\rho\right), \lambda_{21}=-f\left(C_{2}\right) F\left(-C_{1}^{*}\right) / G\left(C_{1},-C_{2},-\rho\right), \lambda_{31}=$ $f\left(C_{1}\right) F\left(C_{2}^{*}\right) / G\left(C_{1}, C_{2}, \rho\right)$ e $\lambda_{32}=f\left(C_{2}\right) F\left(C_{1}^{*}\right) / G\left(C_{1}, C_{2}, \rho\right)$, nos quais

$C_{1}=\hat{\theta}_{1} z_{1}$ e $C_{2}=\hat{\theta}_{2} z_{2}$ são predições lineares de (4) e (5), respectivamente, $C_{1}^{*}=C_{1}-\rho C_{2} / \sqrt{1-\rho^{2}} \mathbf{e} C_{2}^{*}=C_{2}-\rho C_{1} / \sqrt{1-\rho^{2}}$ são combinações das referidas predições,

$G\left(C_{1},-C_{2},-\rho\right)$ é a probabilidade do indivíduo participar do mercado de trabalho e

$G\left(C_{1}, C_{2}, \rho\right)$ é a probabilidade do trabalhador estar empregado,

$f$ é a função de densidade normal,

$F$ é a função de densidade acumulada e

$G$ é a função de densidade normal bivariada (vide Tunali 1986, pp.238,242 e 272-274).

No segundo estágio, os termos de correção $\lambda_{31}$ e $\lambda_{32}$ entram na equação de salários (6) como regressores adicionais, que é regredida em uma amostra composta por participantes e empregados, permitindo o controle dos salários para um potencial duplo viés de seleção envolvido nas condições de participante/não participante e empregado/desempregado. Formalmente, tem-se:

$$
E\left(\ln W_{3} \mid y_{1}=1, y_{2}=1\right)=\hat{\beta}_{3} X_{3}+\hat{\sigma}_{31} \lambda_{31}+\hat{\sigma}_{32} \lambda_{32}
$$

Onde: $\hat{\beta}_{3}$ é um vetor de parâmetros corrigido para viés de seleção na amostra; $\hat{\sigma}_{31}$ é uma estimativa da covariância entre os ternos $\varepsilon_{3}$ e $u_{1}$ e $\hat{\sigma}_{32}$ a covariância entre $\varepsilon_{3}$ e $u_{2}$ (Tunali 1986, p. 237).

\subsection{Estimativa do salário de reserva}

Nesse trabalho, as estimativas dos salários de reserva seguiram o método proposto por Mohanty (2005), que consiste em descontar a utilidade esperada da participação no mercado de trabalho do salário de mercado. Para trabalhadores empregados, por exemplo, cálculo do salário de reserva é dado por:

$$
\ln W_{3}^{r} \equiv E\left(\ln W_{3} \mid y_{1}=1 ; y_{2}=1\right)-C_{1},
$$

onde: $E\left(\ln W_{3} \mid y_{1}=1 ; y_{2}=1\right)$ é o $\log$ do salário-hora predito no mercado, já corrigido para viés de seleção amostral; $C_{1}=\hat{\theta}_{1} z_{1}$ é a predição linear da equação de seleção (4), isto é, uma estimativa da utilidade gerada pela participação no mercado de trabalho. 
Ainda seguindo Mohanty (2005), o cálculo dos salários de reserva contrafactuais, isto é, o salário de reserva dos inativos $\left(\ln W_{1}^{r}\right)$ e dos desocupados $\left(\ln W_{2}^{r}\right)$, corrigidos para viés de seleção, segue a intuição anterior, e foram calculados usando as seguintes equações, respectivamente:

$$
\begin{gathered}
\ln W_{1}^{r} \equiv \hat{\beta}_{3} X_{1}+\left(\hat{\sigma}_{31}+\hat{\sigma}_{32}\right) \lambda_{1}-C_{1} \\
\ln W_{2}^{r} \equiv \hat{\beta}_{3} X_{2}+\hat{\sigma}_{31} \lambda_{21}+\hat{\sigma}_{32} \lambda_{22}-C_{1},
\end{gathered}
$$

onde $X_{1}$ é um vetor de características pessoais dos inativos e $X_{2}$ um vetor de características pessoais dos desocupados.

Portanto, note-se que os cálculos contrafactuais (9)-(10) imputam os parâmetros condicionais dos empregados no mercado de trabalho, obtidos na equação (7), às características observadas e não observadas dos inativos e desocupados, fornecendo uma estimativa do salário de reserva, caso os primeiros se encontrassem participando do mercado e empregados.

\section{Base de dados e Tratamentos}

Para atingir o objetivo proposto, foram utilizados dados obtidos nos arquivos da Pesquisa Nacional por Amostra de Domicílios (PNAD) para o ano de 2006.

A amostra selecionada foi composta por pessoas com idade entre 16 e 65 anos e que possuem pelo menos 1 ano de estudo ${ }^{8}$. No que se refere aos trabalhadores ocupados, considerou-se todos aqueles que estavam inseridos em uma ocupação, tanto de maneira formal quanto informal, excluindo da amostra apenas os trabalhadores por conta-própria, empregadores, aqueles que trabalham para consumo próprio e as pessoas ocupadas que não informaram um salário recebido e/ou número de horas trabalhadas ${ }^{9}$. Após as referidas filtragens, a amostra final foi constituída 188.156 indivíduos, sendo $111.382 \mathrm{ocu}-$ pados, 16.775 desocupados e 59.999 inativos, respectivamente, $59,1 \%, 8,9 \%$ e $31,2 \%$ da amostra total.

Considerando a estratégia empírica anteriormente reportada, foi selecionado um conjunto de atributos socioeconômicos dos indivíduos, a saber: gênero, raça, escolaridade, faixa etária, posição na família, localização e condição de migração. Todas essas características foram incluídas como variáveis de controle nas regressões (4)-(5) e (7). Contudo, algumas variáveis foram excluídas da equação de rendimentos (7) e apenas imputadas no modelo bivariado (4)-(5), como, por exemplo, a condição da pessoa no domicílio e o número de membros do domicílio. Esse procedimento é bastante usado na literatura para a identificação do modelo estrutural, ou seja, isolar os determinantes da oferta de trabalho e da empregabilidade daqueles relacionados aos rendimentos (Heckman 1990, Gobillon \& Le Blanc 2003). O leitor pode encontrar a definição detalhada de cada variável usada nas regressões consultando a Tabela A.1, em apêndice.

\footnotetext{
${ }^{8}$ Com relação a esta última variável, optou-se por retirar da amostra os indivíduos analfabetos pelo fato de que a maioria destes se constituía de inativos, o que poderia tornar os resultados inconsistentes.

${ }^{9}$ A exclusão destas ocupações deve-se a dificuldade teórica de se determinar um salário de reserva para estas categorias. Neste caso, preferiu-se considerar apenas as relações de trabalhos que envolveriam empregados versus empregadores.
} 


\subsection{Análise descritiva da amostra}

A Tabela 1, abaixo, apresenta a distribuição percentual dos trabalhadores segundo a condição de atividade e gênero e por região de residência. É possível observar que a maioria dos desocupados é homem (55\%), enquanto as mulheres predominam nas situações de desemprego $(58 \%)$ e inatividade $(74 \%)$. No Nordeste, o percentual de homens desocupados (44\%) supera a média nacional e aqueles registrados para as demais regiões (42\%). Por outro lado, no Sudeste, o percentual de mulheres desocupadas é de $59,7 \%$, contra $58 \%$ no Brasil. Quanto às outras condições de atividade, nota-se uma regularidade na distribuição regional.

Tabela 1: Brasil: distribuição percentual dos trabalhadores segundo condição de atividade e gênero e por região - 2006

\begin{tabular}{lcccccc}
\hline Gênero / Região & Norte & Nordeste & Sudeste & Sul & Centro-Oeste & Brasil \\
\hline \multicolumn{7}{c}{ Ocupados } \\
\hline Mulher & 42,1 & 44,9 & 45,2 & 47,0 & 44,5 & 45,0 \\
Homem & 57,9 & 55,1 & 54,8 & 53,0 & 55,5 & 55,0 \\
\hline \multicolumn{7}{c}{ Desocupados } \\
\hline Mulher & 58,8 & 56,0 & 59,7 & 58,0 & 58,2 & 58,0 \\
Homem & 41,3 & 44,0 & 40,3 & 42,0 & 41,8 & 42,0 \\
\hline \multicolumn{7}{c}{ Inativos } \\
\hline Mulher & 75,0 & 73,8 & 73,2 & 73,6 & 76,3 & 74,0 \\
Homem & 25,0 & 26,2 & 26,8 & 26,4 & 23,7 & 26,0 \\
Total & 22.750 & 53.106 & 61.215 & 29.161 & 21.924 & 188.156 \\
\hline
\end{tabular}

Fonte: Elaboração própria a partir dos dados da PNAD de 2006.

A Tabela 2, a seguir, reporta a distribuição percentual dos trabalhadores segundo características socioeconômicas e por condição no mercado de trabalho.

Os dados permitem, em geral, caracterizar o indivíduo ocupado típico como: homem de cor não branca, não responsável pela família, com idade entre 41 e 65 anos, com nível de escolaridade entre 10 e 13 anos de estudo, residente em área urbana e não migrante ${ }^{10}$. Já o trabalhador desocupado é mulher de cor não branca, não chefe de família, com idade entre 16 e 20 anos, com nível de escolaridade entre 4 e 10 anos de estudo, residente na zona urbana e não migrante. Por fim, o perfil do trabalhador inativo típico é caracterizado como: mulher de cor não branca, não responsável pelo domicílio, com idade entre 41 e 65 anos, com 4 a 7 anos de estudo, residente no meio urbano e não migrante.

De forma mais especifica, é possível observar mais de 50\% dos trabalhadores ocupados têm mais de 30 anos de idade e $43 \%$ é responsável pela família. Já para os trabalhadores desocupados, verifica-se que o percentual de mulheres desempregadas é $58 \%$, contra $42 \%$ de homens. O percentual de desempregados aumenta, conforme se eleva os anos de estudo até a faixa de escolaridade de 11 a 13 anos de estudo, declinando após esta. Tal resultado

\footnotetext{
${ }^{10}$ Definiu-se como migrante o indivíduo que reside em uma unidade da federação distinta daquela em que nasceu.
} 
Tabela 2: Brasil: Distribuição percentual dos trabalhadores segundo características socioeconômicas e por condição de atividade - 2006

\begin{tabular}{lccc}
\hline & \multicolumn{3}{c}{ Condição no mercado de trabalho } \\
\cline { 2 - 4 } Variável/Condição & Ocupados & Desocupados & Inativos \\
\cline { 2 - 4 } Mulher & 45,0 & 58,0 & 74,0 \\
Homem & 55,0 & 42,0 & 26,0 \\
Não Branco & 51,6 & 59,1 & 52,7 \\
Branco & 48,4 & 40,9 & 47,3 \\
Idade - 16 a 20 & 11,3 & 29,5 & 26,2 \\
Idade - 21 a 24 & 14,0 & 20,4 & 10,6 \\
Idade - 25 a 30 & 20,0 & 18,8 & 11,2 \\
Idade - 31 a 40 & 26,6 & 17,1 & 14,4 \\
Idade - 41 a 65 & 28,1 & 14,1 & 37,6 \\
Estudo - 1 a 3 & 8,3 & 6,7 & 13,2 \\
Estudo - 4 a 7 & 24,0 & 24,6 & 33,0 \\
Estudo - 8 a 10 & 18,8 & 27,8 & 25,8 \\
Estudo - 10 a 13 & 35,8 & 35,8 & 23,0 \\
Estudo - mais de 13 & 13,0 & 5,1 & 5,1 \\
Chefe de família & 42,9 & 19,2 & 20,0 \\
Não Chefe & 57,1 & 80,8 & 80,0 \\
Zona Rural & 9,1 & 5,4 & 10,5 \\
Zona Urbana & 90,9 & 94,6 & 89,5 \\
Não Metrópole & 58,1 & 47,8 & 58,2 \\
Região metropolitana & 41,9 & 52,2 & 41,8 \\
Não Migrante & 80,7 & 85,3 & 81,6 \\
Migrante & 19,3 & 14,7 & 18,4 \\
Região Norte & 11,5 & 11,0 & 13,5 \\
Região Nordeste & 25,7 & 33,6 & 31,5 \\
Região Sudeste & 33,7 & 32,7 & 30,3 \\
Região Sul & 16,9 & 11,9 & 13,8 \\
Região Centro-Oeste & 12,2 & 10,8 & 10,9 \\
\hline Fonte: Elaboraça própria a partir & \\
Idos dados da PNAD & 2006 \\
\hline
\end{tabular}

Fonte: Elaboração própria a partir dos dados da PNAD de 2006.

pode ser explicado pela maior exigência, em termos salariais, demonstrada pelos trabalhadores que possuem um maior nível de escolaridade (Kiefer \& Neumann 1979, Rõõm 2003, Oliveira \& Carvalho 2006). Por outro lado, a maior concentração dos trabalhadores desocupados nas faixas etárias de 16 a 20 anos e de 21 a 24 anos de idade $(49,9 \%)$ e como não responsáveis pelo domicílio $(80,8 \%)$, sugere que os jovens enfrentam dificuldades na busca por uma ocupação, possivelmente, relacionadas à falta de experiência ${ }^{11}$.

Por sua vez, na parcela composta por inativos, destaca-se, principalmente, o elevado percentual de mulheres $(74 \%)$ e a concentração nas faixas de 16 a 20 anos e de 41 a 65 anos de idade. Isso se verifica pelo fato de que, dentre os mais velhos, cerca de 32,8\% recebem o beneficio da aposentadoria e, dentre os jovens, mais de $70 \%$ são estudantes, razões estas que podem servir de explicação também para a distribuição dos mesmos entre os níveis de escolaridade ${ }^{12}$.

\footnotetext{
${ }^{11}$ Segundo Kassouf \& Silva (2002), esta é uma característica comum do mercado de trabalho brasileiro que reflete a maior dificuldade dos jovens brasileiros em conseguir uma inserção ocupacional.

${ }^{12}$ Apesar de esses dados não serem apresentados na Tabela 2, podem ser prontamente fornecidos pelos autores.
} 


\section{Estimação e análise dos resultados empíricos}

Conforme já explicitado, o conceito de salário de reserva denota, em um primeiro momento, uma preferência do indivíduo em se inserir no mercado de trabalho. Além disso, existe também a preferência do empregador no processo de contratação do mesmo. Da relação entre trabalhadores e empregadores surge o conflito referente à questão salarial, por um lado, encontra-se o trabalhador que não detém todas as informações acerca do funcionamento do mercado de trabalho e determina, embora que de maneira subjetiva, o seu salário de reserva, e, por outro, o demandante, que está disposto a pagar um determinado nível de salário.

Partindo dos elementos teóricos do salário de reserva, considerou-se necessária a análise das probabilidades de inserção ocupacional dos indivíduos, através das chances de participação no mercado de trabalho e das chances de contratação, para, a partir dessa observação, apresentar o salário de reserva médio, condicionado às referidas probabilidades e estimado de acordo com características pessoais e regionais de indivíduos ocupados, desocupados e inativos.

\subsection{Determinantes da oferta de trabalho, empregabilidade e dos rendimentos}

Para analisar a probabilidade dos indivíduos encontrarem-se ocupados, foi estimado por Máxima Verossimilhança, inicialmente para a amostra total, o modelo probit bivariado de seleção amostral (4)-(5), que considera a determinação conjunta da probabilidade dos indivíduos participarem no mercado de trabalho (preferência do trabalhador) e da probabilidade destes serem contratados pelo empregador (preferência do empregador). Em seguida, foi realizada a regressão da equação de salários (7) por MQO, considerando os termos de correção para viés de seleção na amostra. Os resultados são apresentados na Tabela 3, a seguir.

As colunas (1) e (2) registram os resultados provenientes da estimação do probit bivariado (4)-(5), onde são apresentados os coeficientes estimados e os efeitos marginais sobre as probabilidades de oferta de trabalho e de emprego, respectivamente ${ }^{13}$. Já na coluna (3) encontram-se os resultados para a regressão linear de salários, corrigida para o viés de seleção amostral.

Em linhas gerais, os resultados mostram que as probabilidades de oferta de trabalho e de conseguir um emprego são diretamente relacionadas com o gênero (masculino), a idade (experiência), o nível de escolaridade, a posição de chefia familiar e a raça (não branca). Por outro lado, as mesmas probabilidades são afetadas negativamente para os residentes em áreas urbanas e/ou metropolitanas, fato consistente com a maior competição por emprego e o maior nível de desemprego nessas regiões.

Os salários dos trabalhadores ocupados são maiores para os homens de cor branca, migrantes, residentes em zonas urbanas e/ou metrópoles. Há retornos salariais crescentes com o aumento da faixa de instrução e não lineares com a idade (experiência). Tais resultados revelam a importância do investimento em capital humano e treinamento e são consistentes com aqueles verificados

\footnotetext{
${ }^{13}$ A partir dos sinais dos coeficientes estimados pode-se analisar a correlação entre os atributos individuais e as probabilidades em foco. Já os efeitos marginais, fornecem o impacto de uma mudança unitária em cada atributo sobre a variação percentual da probabilidade.
} 


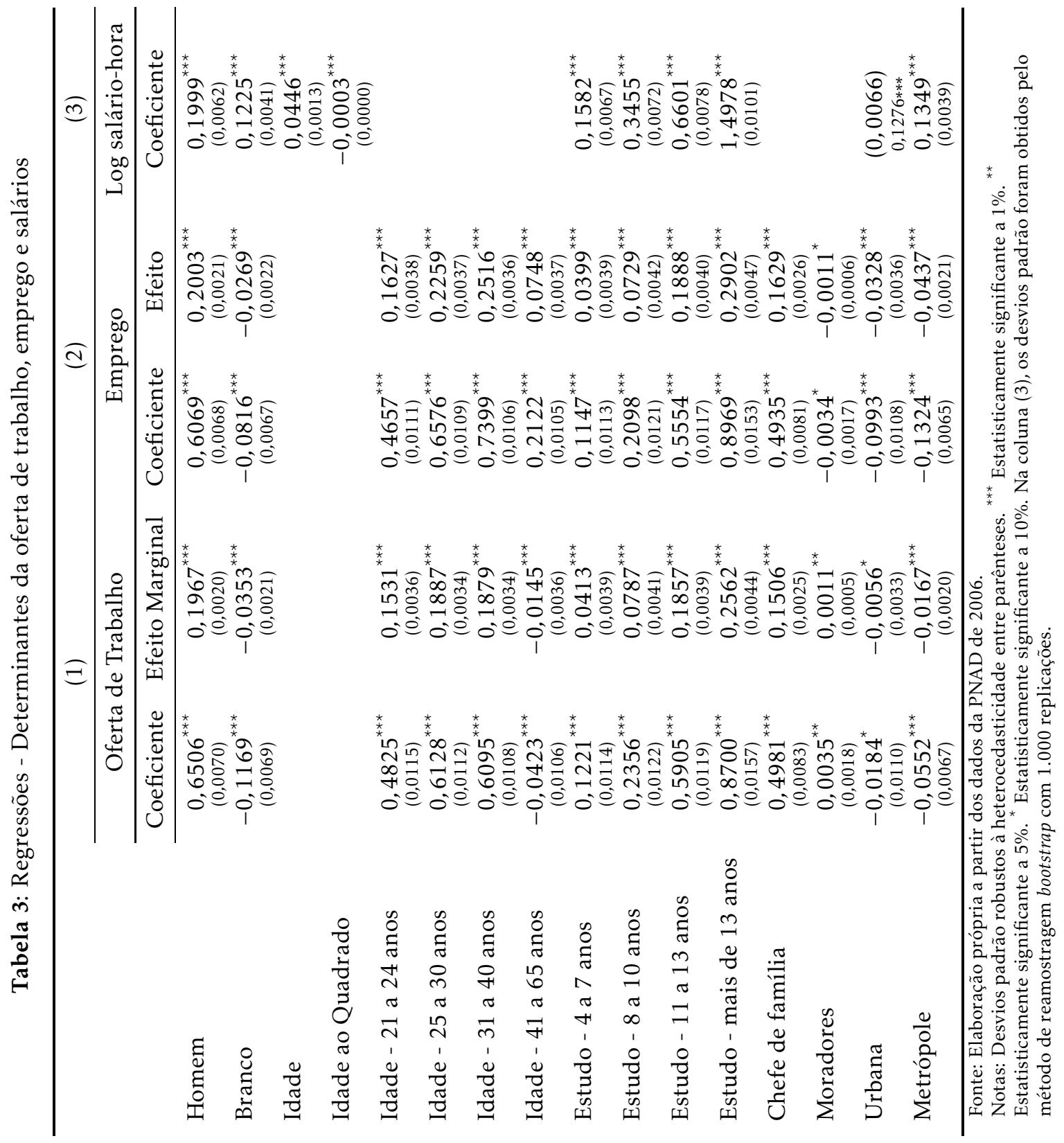




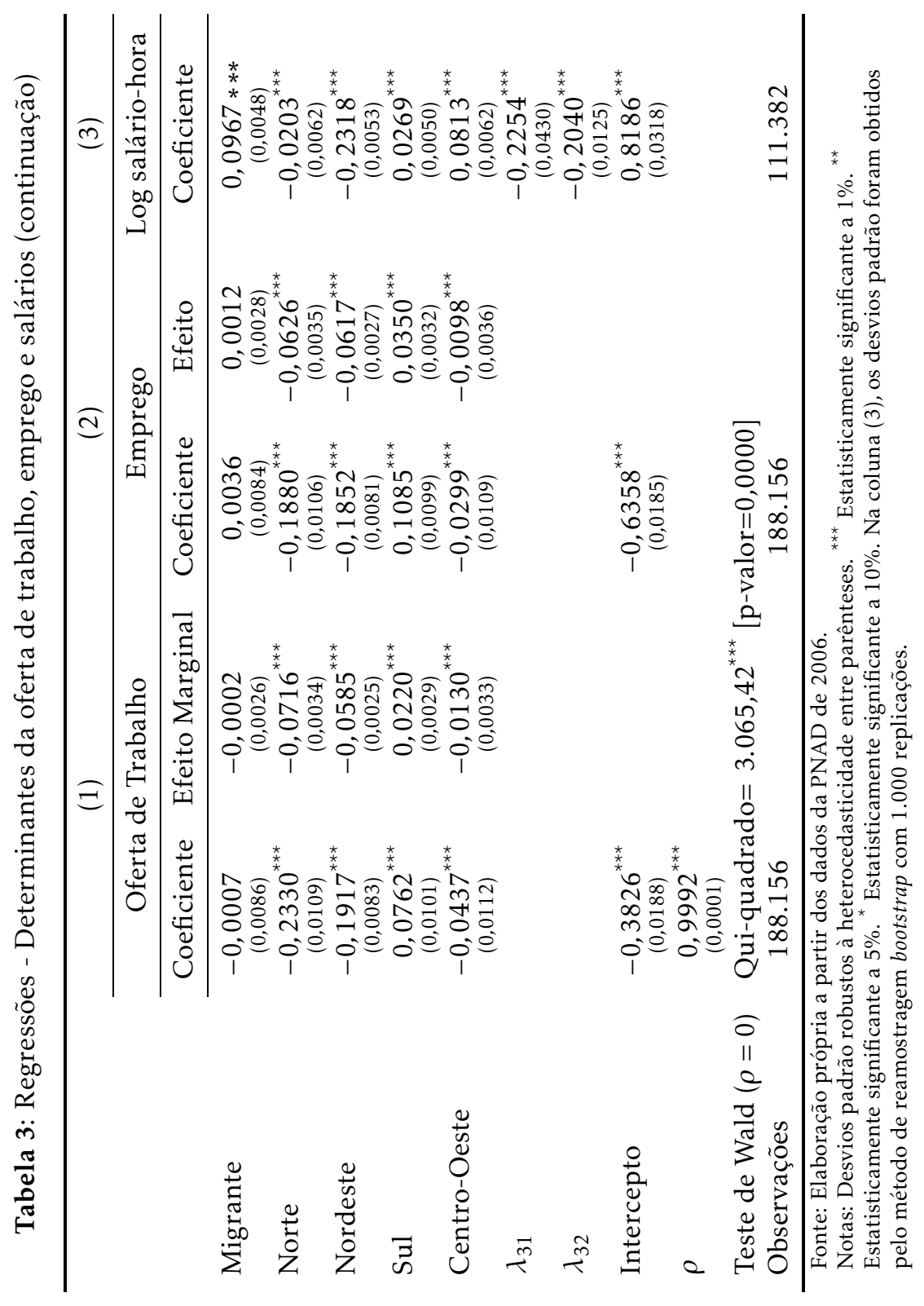


em vários estudos sobre mercado de trabalho e diferenciais salariais no Brasil (Barros et al. 1995, Mendonça \& R. 1995, Santos Junior et al. 2005,?, Barros et al. 1995, Mendonça \& R. 1995, Santos Junior et al. 2005,?).

Observando os efeitos marginais é possível verificar que os homens são mais propensos à participação no mercado de trabalho e à obtenção de emprego do que as mulheres, sendo estas probabilidades superiores em 19,6 p.p. e 20 p.p., respectivamente. O impacto do investimento em capital humano não é desprezível. As evidências sugerem que as probabilidades de oferta de trabalho e de contratação aumentam, consideravelmente, até os 40 anos de idade $^{14}$ e com a elevação dos anos de estudo. Por exemplo, comparando um indivíduo com mais de 13 anos de estudo com outro que registra entre 1 e 3 anos (categoria base), a chance de o primeiro ingressar no mercado de trabalho é 25 p.p. maior e a probabilidade de emprego é superior em 29 p.p. Ainda no tocante à idade, é possível observar que um indivíduo com idade entre 31 e 40 anos tem suas chances de ofertar trabalho e de conseguir emprego aumentadas em 18,7 p.p. e 25 p.p., respectivamente, quando comparada a um indivíduo com idade entre 16 e 20 anos (categoria omitida).

As variáveis relacionadas à posição na família e ao número de moradores no domicilio, usadas a identificação estrutural do modelo em foco, revelaramse estatisticamente significativas. Os chefes de família, por exemplo, são mais propensos a ofertar trabalho (conseguir emprego) em 15 p.p. (16 p.p) quando comparados aos outros membros da família. Por sua vez, enquanto um morador a mais no domicilio eleva em 0,1 p.p. a probabilidade de ingresso do individuo típico no mercado de trabalho, reduz, no mesmo patamar, a chance de contratação.

Há diferenças regionais consistentes com as estruturas heterogêneas dos mercados de trabalho no Brasil. Uma pessoa residente nas regiões Norte ou Nordeste registra menor probabilidade de ingresso no mercado e de emprego, assim como menor salário, caso se ache empregada, se comparada à outra moradora da região Sudeste (categoria de referencia). Apenas os residentes nas regiões Sul e Centro-Oeste registram maior rendimento médio que os moradores do Sudeste, sendo que na primeira região, as chances de ofertar trabalho e de ser contratado aumentam, enquanto, na última, são relativamente menores.

Por fim, cabe ressaltar que o coeficiente de correlação entre os resíduos do probit bivariado foi estatisticamente diferente de zero e próximo a 1, o que sugere que as decisões de ofertar horas de trabalho e de conseguir um emprego são diretamente correlacionadas e interdependentes. Por outro lado, os coeficientes relacionados às variáveis de correção para viés de seleção amostral, na equação de salários, foram estatisticamente significativos, confirmando a hipótese de não aleatoriedade dos trabalhadores na amostra e a consistência da estratégia empírica utilizada.

\subsection{Estimativas de Salário de Reserva}

Nesta subseção, faz-se uma análise dos salários de reserva estimados para os indivíduos ocupados, desocupados e inativos. Vale ressaltar que, doravante, os salários estão em $\mathrm{R} \$$ por horas de trabalho semanais e seus valores médios

\footnotetext{
${ }^{14}$ A relação entre idade e oferta de trabalho é inversa para pessoas na faixa etária de 41 a 65 anos, possivelmente, associado ao considerável número de aposentados nesse grupo.
} 
foram controlados de acordo com as variáveis socioeconômicas selecionadas, a saber: gênero, raça, escolaridade, idade, posição na familiar, condição de migração e localização.

\section{Salário de reserva dos trabalhadores ocupados}

Dado que as informações do salário de mercado são observadas, especificamente, para os trabalhadores ocupados, é possível, a partir de predições lineares das equações (4) e (7), obter o salário de reserva médio por hora, conforme cálculo sintetizado pela equação $(8)^{15}$. Destarte, a Tabela 4 , a seguir, registra os valores médios dos salários-hora de reserva em amostras controladas segundo diferentes características socioeconômicas e por macrorregiões. Dada à estrutura multidimensional da análise, tornou-se factível testar, estatisticamente, as diferenças de médias apenas entre os atributos socioeconômicos e em relação a uma única categoria de referência, quando as características envolvem mais de duas categorias ${ }^{16}$.

Os resultados mostram que, em termos de gênero, as mulheres, em todas as regiões, apresentam um salário de reserva quase duas vezes superior àquele registrado para os homens (média de $\mathrm{R} \$ 10,45$ por hora, contra $\mathrm{R} \$ 5,45$ para o Brasil), embora seja importante destacar que o desvio padrão é, relativamente, maior entre as mulheres. Os trabalhadores de cor branca também apresentam salário de reserva superior ao verificado para os de raça não branca, ou seja, uma média de $R \$ 3,00$ por hora acima do revelado pelos não brancos. Tais evidências sugerem que fatores sociais relacionados à discriminação por gênero e/ou raça podem afetar as preferências dos trabalhadores quanto à oferta individual de mão de obra, e não apenas os salários de mercado no Brasil ${ }^{17}$.

As evidências também são bastante sugestivas em termos da influência dos diferenciais de custo de vida e de migração na propensão ao ingresso no mercado de trabalho. Nesse sentido, os dados mostram que, entre os trabalhadores ocupados, os salários de reserva são maiores nas zonas urbanas e/ou em regiões metropolitanas, comparados aos rendimentos exigidos por trabalhadores residentes no meio rural ou em pequenas e médias cidades. Tais evidências podem revelar maior compensação pelo custo vida, que, geralmente, é maior nas zonas urbanas das grandes cidades ${ }^{18}$. Já o maior salário de reserva, exigido pelo trabalhador migrante, provavelmente é justificado pelo investimento feito na migração e pelos custos de adaptação local.

Outras evidências interessantes são observadas a partir da comparação dos salários de reserva entre as faixas etárias e faixa de escolaridade. Entre os trabalhadores de 16 a 40 anos e para aqueles que registram entre 1 e 13 anos de estudo, os salários de reserva estimados não apresentam grandes diferenças,

\footnotetext{
${ }^{15}$ Os salários-hora foram, inicialmente, calculados em logaritmo, conforme a equação (8). Para obter os valores em R\$, aplicou-se o operador exponencial.

${ }^{16}$ Foram efetuados, considerando apenas tabela em foco, 84 testes $t$-student de diferença de média para diferentes grupos em amostras controladas por regiões. Dado o grande de número de resultados, optou-se por destacar, na tabela 4 , apenas os resultados não significativos.

${ }^{17}$ Segundo Oliveira \& Carvalho (2006), o fato de as mulheres exercerem atividades dentro e fora do domicílio pode fazer com que elas incorporem esse fator na expectativa salarial, aumentando seu salário de reserva.

${ }^{18}$ Esses resultados também são condizentes com uma das hipóteses testadas por Hofler \& Murphy (1994) e Mohanty (2005), a qual aponta, em linhas gerais, que os trabalhadores residentes em áreas urbanas têm salários de reserva mais altos, devido ao fato das firmas serem menos dispersas, geograficamente, e de se ter um melhor acesso às redes de transporte, determinando menores custos de se procurar outro emprego.
} 
Tabela 4: Brasil: salário-hora de reserva médio para trabalhadores ocupados segundo características individuais e por regiões - 2006 $(\mathrm{em} \mathrm{R} \$)$

\begin{tabular}{|c|c|c|c|c|c|c|}
\hline & Norte & Nordeste & Sudeste & Sul & Centro-Oeste & Total \\
\hline Mulher $^{b}$ & $\begin{array}{r}10,78 \\
(6,86)\end{array}$ & $\begin{array}{l}8,90 \\
(5,81)\end{array}$ & $\begin{array}{r}10,94 \\
(6,75)\end{array}$ & $\begin{array}{r}10,77 \\
(6,29)\end{array}$ & $\begin{array}{r}11,56 \\
(7,52)\end{array}$ & $\begin{array}{r}10,45 \\
(6,62)\end{array}$ \\
\hline Homem & $\begin{array}{l}5,76 \\
(3,42)\end{array}$ & $\begin{array}{c}4,65 \\
(2,82)\end{array}$ & $\begin{array}{l}5,70 \\
(3,30)\end{array}$ & $\begin{array}{l}5,65 \\
(3,12)\end{array}$ & $\begin{array}{r}5,89 \\
(3,63)\end{array}$ & $\begin{array}{c}5,45 \\
(3,25)\end{array}$ \\
\hline Não branco ${ }^{b}$ & $\begin{array}{l}7,07 \\
(4,85)\end{array}$ & $\begin{array}{r}5,69 \\
(3,83)\end{array}$ & $\begin{array}{r}6,39 \\
(4,11)\end{array}$ & $\begin{array}{l}5,88 \\
(3,73)\end{array}$ & $\begin{array}{r}6,86 \\
(4,72)\end{array}$ & $\begin{array}{r}6,29 \\
(4,24)\end{array}$ \\
\hline Branco & $\begin{array}{r}10,05 \\
(7,14)\end{array}$ & $\begin{array}{r}8,59 \\
(6,33)\end{array}$ & $\begin{array}{c}9,41 \\
(6,51)\end{array}$ & $\begin{array}{c}8,61 \\
(5,74)\end{array}$ & $\begin{array}{r}10,45 \\
(7,55)\end{array}$ & $\begin{array}{c}9,21 \\
(6,48)\end{array}$ \\
\hline Não chefe ${ }^{b}$ & $\begin{array}{l}8,96 \\
(6,30)\end{array}$ & $\begin{array}{c}7,42 \\
(5,37)\end{array}$ & $\begin{array}{c}9,18 \\
(6,39)\end{array}$ & $\begin{array}{l}9,24 \\
(6,06)\end{array}$ & $\begin{array}{r}9,73 \\
(7,01)\end{array}$ & $\begin{array}{c}8,77 \\
(6,20)\end{array}$ \\
\hline Chefe de família & $\begin{array}{l}6,50 \\
(4,52)\end{array}$ & $\begin{array}{c}5,36 \\
(3,85)\end{array}$ & $\begin{array}{c}6,57 \\
(4,40)\end{array}$ & $\begin{array}{c}6,49 \\
(4,19)\end{array}$ & $\begin{array}{c}6,81 \\
(5,03)\end{array}$ & $\begin{array}{c}6,28 \\
(4,37)\end{array}$ \\
\hline Idade 016 a $20^{b}$ & $\begin{array}{l}6,94 \\
(2,21)\end{array}$ & $\begin{array}{r}5,49 \\
(1,68)\end{array}$ & $\begin{array}{r}6,65 \\
(1,94)\end{array}$ & $\begin{array}{l}6,78 \\
(1,92)\end{array}$ & $\begin{array}{c}6,92 \\
(2,12)\end{array}$ & $\begin{array}{c}6,44 \\
(2,02)\end{array}$ \\
\hline Idade 021 a 24 & $\begin{array}{l}5,32 \\
(2,35)\end{array}$ & $\begin{array}{c}4,37 \\
(1,98)\end{array}$ & $\begin{array}{l}5,31 \\
(2,43)\end{array}$ & $\begin{array}{l}5,41 \\
(2,37)\end{array}$ & $\begin{array}{l}5,66 \\
(2,65)\end{array}$ & $\begin{array}{c}5,12 \\
(2,37)\end{array}$ \\
\hline Idade 025 a 30 & $\begin{array}{l}5,32 \\
(2,64)\end{array}$ & $\begin{array}{c}4,47 \\
(2,36)\end{array}$ & $\begin{array}{l}5,44 \\
(2,90)\end{array}$ & $\begin{array}{l}5,40 \\
(2,77)\end{array}$ & $\begin{array}{c}5,78 \\
(3,39)\end{array}$ & $\begin{array}{l}5,20 \\
(2,82)\end{array}$ \\
\hline Idade 031 a 40 & $\begin{array}{l}6,41 \\
(3,52)\end{array}$ & $\begin{array}{l}5,21 \\
(2,92)\end{array}$ & $\begin{array}{l}6,07 \\
(3,39)\end{array}$ & $\begin{array}{c}6,18 \\
(3,29)\end{array}$ & $\begin{array}{r}6,75 \\
(4,06)\end{array}$ & $\begin{array}{r}5,99 \\
(3,41)\end{array}$ \\
\hline Idade 041 a 65 & $\begin{array}{r}13,96 \\
(7,80)\end{array}$ & $\begin{array}{r}11,50 \\
(6,62)\end{array}$ & $\begin{array}{r}13,02 \\
(7,27)\end{array}$ & $\begin{array}{r}12,93 \\
(6,84)\end{array}$ & $\begin{array}{r}14,48 \\
(8,57)\end{array}$ & $\begin{array}{r}12,91 \\
(7,32)\end{array}$ \\
\hline Estudo 01 a $3^{b}$ & $\begin{array}{l}6,18 \\
(3,62)\end{array}$ & $\begin{array}{c}4,81 \\
(2,96)\end{array}$ & $\begin{array}{c}6,77 \\
(4,01)\end{array}$ & $\begin{array}{c}7,35 \\
(4,22)\end{array}$ & $\begin{array}{c}6,78 \\
(4,11)\end{array}$ & $\begin{array}{c}6,07 \\
(3,79)\end{array}$ \\
\hline Estudo 04 a 7 & $\begin{array}{c}6,38^{*} \\
(3,62)\end{array}$ & $\begin{array}{c}5,22 \\
(3,03)\end{array}$ & $\begin{array}{l}6,81^{*} \\
(4,05)\end{array}$ & $\begin{array}{l}7,03 \\
(4,13)\end{array}$ & $\begin{array}{c}6,30 \\
(3,77)\end{array}$ & $\begin{array}{r}6,32 \\
(3,80)\end{array}$ \\
\hline Estudo 08 a 10 & $\begin{array}{c}6,70 \\
(3,49)\end{array}$ & $\begin{array}{l}5,52 \\
(2,90)\end{array}$ & $\begin{array}{l}6,77^{*} \\
(3,79)\end{array}$ & $\begin{array}{l}6,83^{*} \\
(3,78)\end{array}$ & $\begin{array}{l}6,77^{*} \\
(3,54)\end{array}$ & $\begin{array}{c}6,47 \\
(3,57)\end{array}$ \\
\hline Estudo 011 a 13 & $\begin{array}{l}7,13 \\
(3,97)\end{array}$ & $\begin{array}{r}6,04 \\
(3,24)\end{array}$ & $\begin{array}{c}6,86^{*} \\
(3,81)\end{array}$ & $\begin{array}{c}6,92 \\
(3,81)\end{array}$ & $\begin{array}{c}7,39 \\
(4,17)\end{array}$ & $\begin{array}{r}6,75 \\
(3,76)\end{array}$ \\
\hline Estudo 0 mais de 13 & $\begin{array}{r}16,87 \\
(9,49)\end{array}$ & $\begin{array}{r}14,70 \\
(8,05)\end{array}$ & $\begin{array}{r}15,80 \\
(8,76)\end{array}$ & $\begin{array}{r}14,86 \\
(8,31)\end{array}$ & $\begin{array}{r}16,82 \\
(9,62)\end{array}$ & $\begin{array}{r}15,65 \\
(8,77)\end{array}$ \\
\hline Rural $^{b}$ & $\begin{array}{l}5,72 \\
(3,91)\end{array}$ & $\begin{array}{l}4,20 \\
(2,76)\end{array}$ & $\begin{array}{c}5,22 \\
(3,35)\end{array}$ & $\begin{array}{l}5,93 \\
(3,94)\end{array}$ & $\begin{array}{c}5,72 \\
(4,06)\end{array}$ & $\begin{array}{c}5,14 \\
(3,54)\end{array}$ \\
\hline Urbana & $\begin{array}{r}8,19 \\
(5,87)\end{array}$ & $\begin{array}{c}6,87 \\
(5,03)\end{array}$ & $\begin{array}{c}8,26 \\
(5,85)\end{array}$ & $\begin{array}{c}8,24 \\
(5,58)\end{array}$ & $\begin{array}{r}8,70 \\
(6,49)\end{array}$ & $\begin{array}{r}7,95 \\
(5,74)\end{array}$ \\
\hline Não metrópole ${ }^{b}$ & $\begin{array}{l}7,27 \\
(5,19)\end{array}$ & $\begin{array}{l}5,75 \\
(4,31)\end{array}$ & $\begin{array}{l}7,16 \\
(4,98)\end{array}$ & $\begin{array}{c}7,28 \\
(4,94)\end{array}$ & $\begin{array}{l}7,53 \\
(5,47)\end{array}$ & $\begin{array}{r}6,92 \\
(4,98)\end{array}$ \\
\hline Metrópole & $\begin{array}{c}9,75 \\
(6,80)\end{array}$ & $\begin{array}{c}7,47 \\
(5,34)\end{array}$ & $\begin{array}{c}9,17 \\
(6,44)\end{array}$ & $\begin{array}{c}8,91 \\
(5,95)\end{array}$ & $\begin{array}{r}10,50 \\
(7,69)\end{array}$ & $\begin{array}{l}8,78 \\
(6,27)\end{array}$ \\
\hline Não migrante ${ }^{b}$ & $\begin{array}{l}7,56 \\
(5,36)\end{array}$ & $\begin{array}{c}6,40 \\
(4,71)\end{array}$ & $\begin{array}{c}7,93 \\
(5,71)\end{array}$ & $\begin{array}{c}7,91 \\
(5,39)\end{array}$ & $\begin{array}{c}7,26 \\
(4,93)\end{array}$ & $\begin{array}{r}7,39 \\
(5,31)\end{array}$ \\
\hline Migrante & $\begin{array}{l}8,69 \\
(6,48)\end{array}$ & $\begin{array}{c}8,22 \\
(6,35)\end{array}$ & $\begin{array}{l}8,65 \\
(6,03)\end{array}$ & $\begin{array}{l}9,14 \\
(6,03)\end{array}$ & $\begin{array}{r}9,85 \\
(7,54)\end{array}$ & $\begin{array}{r}8,99 \\
(6,64)\end{array}$ \\
\hline
\end{tabular}

Fonte: Elaboração própria a partir dos dados da PNAD de 2006. Os valores entre parênteses correspondem ao desvio padrão. b Categoria de referência no teste $t$-student para diferença de médias. ${ }^{*}$ Diferença de média em relação à categoria base não é estatisticamente significativa a 5\%. 
girando em torno de $\mathrm{R} \$ 5$ por hora, no primeiro grupo e em $\mathrm{R} \$ 6$ por hora, no segundo ${ }^{19}$. No entanto, ao se comparar esses valores com aqueles observados para os trabalhadores mais experientes ( 41 a 65 anos) e altamente instruídos (mais de 13 anos de estudo), percebe-se que, em geral, o salário de reserva médio mais que dobra. Esses resultados podem estar relacionados, por um lado, a elevada escassez de mão de obra qualificada no Brasil Menezes Filho \& Jr. (2003), e, por outro, a compensação pelo investimento em capital humano ${ }^{20}$. Mohanty (2005) e Hofler \& Murphy (1994), por exemplo, argumentam que os trabalhadores mais educados fixarão salários de reserva mais altos, tornando mais eficiente o esforço de procura por emprego, já que, devido ao maior treinamento e melhor acesso a informações, espera-se que esses trabalhadores incorram em mais baixos custos de procura.

Por fim, os dados da Tabela 4, sugerem que a responsabilidade familiar reduz a exigência do trabalhador quando à entrada no mercado de trabalho. Enquanto, no Brasil, um chefe de família revela um salário-hora de reserva de $\mathrm{R} \$ 6,30$, a pessoa não chefe, em média, registra $\mathrm{R} \$ 8,77$ por hora.

\section{Salário de reserva dos trabalhadores desempregados}

Os salários de reserva, estimados para os trabalhadores desocupados no Brasil, são apresentados na Tabela 5, abaixo, e estratificados segundo as características socioeconômicas e por regiões. Tais resultados foram calculados a partir da equação (10), ou seja, nesse exercício contrafactual foram usados os coeficientes estimados na equação (7), imputados às características das pessoas desocupadas e a predição linear da equação de oferta de trabalho (4).

Os dados guardam, em geral, regularidades com os observados anteriormente para os trabalhadores ocupados, sobretudo, no tocante às diferenças de salário de reserva por gênero, raça, posição familiar, condição de migração, experiência, nível de escolaridade e localização.

Contudo, há algumas diferenças importantes entre os salários de reserva dos trabalhadores ocupados e desocupados. A primeira deve-se ao fato de o salário de reserva dos desempregados na faixa etária de 16 a 20 anos (jovens) ser, em média, maior que o verificado para os trabalhadores ocupados na mesma faixa (ver Tabela 4). Tal evidência pode se relacionar ao custo de oportunidade que permeia a decisão entre estudo e trabalho ${ }^{21}$. Em segundo lugar, observa-se que os trabalhadores desocupados mais instruídos, isto é, com mais de 13 anos de estudo registram salário-hora de reserva, em média, maior que o observado para o grupo dos ocupados, fato que pode, em parte, justificar a persistência dos primeiros na condição de desempregados ${ }^{22}$.

\section{Salário de reserva dos indivíduos inativos}

A literatura empírica, sobre salário de reserva, apresenta maior foco de estudo de trabalhadores desocupados e ocupados, sendo poucas as pesquisas existentes acerca dos inativos. Nesse contexto, cabe destacar os estudos de Blackaby

\footnotetext{
${ }^{19}$ Oliveira \& Carvalho (2006) observaram que um ano a mais na idade implica numa pequena elevação no valor estimado do salário de reserva.

${ }^{20}$ Outro fator explicativo seria o impacto da renda do não trabalho entre os aposentados.

${ }^{21}$ As estatísticas da amostra revelam que a maioria dos desempregados tem entre 16 e 20 anos de idade e que não são responsáveis pelo domicílio (vide Tabela 2).

${ }^{22}$ As diferenças de média reportadas são estatisticamente significativas a $5 \%$ no teste $t$-student.
} 
Tabela 5: Brasil: salário-hora de reserva médio para trabalhadores desocupados, segundo características individuais e regiões - 2006 (em R\$)

\begin{tabular}{|c|c|c|c|c|c|c|}
\hline & Norte & Nordeste & Sudeste & Sul & Centro-Oeste & Total \\
\hline Mulher $^{b}$ & $\begin{array}{l}9,26 \\
(3,49)\end{array}$ & $\begin{array}{l}7,83 \\
(3,21)\end{array}$ & $\begin{array}{r}9,74 \\
(4,51)\end{array}$ & $\begin{array}{r}9,73 \\
(4,12)\end{array}$ & $\begin{array}{r}10,05 \\
(4,72)\end{array}$ & $\begin{array}{c}9,10 \\
(4,10)\end{array}$ \\
\hline Homem & $\begin{array}{l}6,58 \\
(2,48)\end{array}$ & $\begin{array}{l}5,45 \\
(2,18)\end{array}$ & $\begin{array}{c}6,91 \\
(2,93)\end{array}$ & $\begin{array}{c}6,74 \\
(2,81)\end{array}$ & $\begin{array}{c}6,76 \\
(2,55)\end{array}$ & $\begin{array}{l}6,32 \\
(2,66)\end{array}$ \\
\hline Não branco ${ }^{b}$ & $\begin{array}{l}7,59 \\
(2,84)\end{array}$ & $\begin{array}{c}6,28 \\
(2,51)\end{array}$ & $\begin{array}{l}7,37 \\
(3,05)\end{array}$ & $\begin{array}{r}6,80 \\
(2,67)\end{array}$ & $\begin{array}{r}7,65 \\
(3,08)\end{array}$ & $\begin{array}{l}6,94 \\
(2,85)\end{array}$ \\
\hline Branco & $\begin{array}{c}9,87 \\
(4,24)\end{array}$ & $\begin{array}{c}8,31 \\
(3,90)\end{array}$ & $\begin{array}{c}9,77 \\
(4,75)\end{array}$ & $\begin{array}{c}9,01 \\
(4,09)\end{array}$ & $\begin{array}{r}10,41 \\
(5,34)\end{array}$ & $\begin{array}{c}9,37 \\
(4,53)\end{array}$ \\
\hline Não chefe ${ }^{b}$ & $\begin{array}{l}8,49 \\
(3,36)\end{array}$ & $\begin{array}{l}7,05 \\
(3,02)\end{array}$ & $\begin{array}{l}8,80 \\
(4,22)\end{array}$ & $\begin{array}{c}8,83 \\
(3,99)\end{array}$ & $\begin{array}{c}9,01 \\
(4,16)\end{array}$ & $\begin{array}{l}8,20 \\
(3,82)\end{array}$ \\
\hline Chefe de família & $\begin{array}{c}6,51 \\
(2,97)\end{array}$ & $\begin{array}{l}5,66 \\
(2,87)\end{array}$ & $\begin{array}{l}7,78 \\
(3,97)\end{array}$ & $\begin{array}{l}7,22 \\
(3,33)\end{array}$ & $\begin{array}{l}7,24 \\
(4,52)\end{array}$ & $\begin{array}{c}6,82 \\
(3,64)\end{array}$ \\
\hline Idade - 16 a $20^{b}$ & $\begin{array}{l}8,40 \\
(2,16)\end{array}$ & $\begin{array}{r}6,90 \\
(1,78)\end{array}$ & $\begin{array}{c}8,06 \\
(1,98)\end{array}$ & $\begin{array}{l}8,17 \\
(1,91)\end{array}$ & $\begin{array}{c}8,42 \\
(2,26)\end{array}$ & $\begin{array}{l}7,77 \\
(2,06)\end{array}$ \\
\hline Idade - 21 a 24 & $\begin{array}{l}7,18 \\
(2,32)\end{array}$ & $\begin{array}{c}5,63 \\
(1,82)\end{array}$ & $\begin{array}{c}6,82 \\
(2,35)\end{array}$ & $\begin{array}{l}7,01 \\
(2,90)\end{array}$ & $\begin{array}{l}7,30 \\
(2,78)\end{array}$ & $\begin{array}{l}6,50 \\
(2,39)\end{array}$ \\
\hline Idade - 25 a 30 & $\begin{array}{l}6,80 \\
(2,39)\end{array}$ & $\begin{array}{l}5,74 \\
(2,23)\end{array}$ & $\begin{array}{l}7,25 \\
(3,07)\end{array}$ & $\begin{array}{c}7,02 \\
(2,88)\end{array}$ & $\begin{array}{l}7,67 \\
(3,34)\end{array}$ & $\begin{array}{l}6,69 \\
(2,82)\end{array}$ \\
\hline Idade - 31 a 40 & $\begin{array}{l}8,01^{*} \\
(3,29)\end{array}$ & $\begin{array}{c}6,33 \\
(2,63)\end{array}$ & $\begin{array}{l}7,92^{*} \\
(3,33)\end{array}$ & $\begin{array}{l}7,76 \\
(3,15)\end{array}$ & $\begin{array}{l}8,12^{*} \\
(3,45)\end{array}$ & $\begin{array}{l}7,37 \\
(3,18)\end{array}$ \\
\hline Idade - 41 a 65 & $\begin{array}{r}13,09 \\
(5,50)\end{array}$ & $\begin{array}{r}11,10 \\
(4,77)\end{array}$ & $\begin{array}{r}13,49 \\
(6,16)\end{array}$ & $\begin{array}{r}12,42 \\
(5,82)\end{array}$ & $\begin{array}{r}14,04 \\
(7,68)\end{array}$ & $\begin{array}{r}12,67 \\
(5,96)\end{array}$ \\
\hline Estudo - 1 a $3^{b}$ & $\begin{array}{c}6,78 \\
(2,74)\end{array}$ & $\begin{array}{l}5,62 \\
(2,61)\end{array}$ & $\begin{array}{c}7,74 \\
(3,53)\end{array}$ & $\begin{array}{r}7,60 \\
(3,43)\end{array}$ & $\begin{array}{r}7,56 \\
(3,33)\end{array}$ & $\begin{array}{c}6,74 \\
(3,21)\end{array}$ \\
\hline Estudo - 4 a 7 & $\begin{array}{l}7,30^{*} \\
(2,86)\end{array}$ & $\begin{array}{l}5,86^{*} \\
(2,33)\end{array}$ & $\begin{array}{l}7,55^{*} \\
(3,19)\end{array}$ & $\begin{array}{l}7,45^{*} \\
(3,15)\end{array}$ & $\begin{array}{l}7,20^{*} \\
(2,54)\end{array}$ & $\begin{array}{l}6,86^{*} \\
(2,89)\end{array}$ \\
\hline Estudo - 8 a 10 & $\begin{array}{l}8,08 \\
(2,73)\end{array}$ & $\begin{array}{c}6,68 \\
(2,32)\end{array}$ & $\begin{array}{l}7,96^{*} \\
(2,87)\end{array}$ & $\begin{array}{l}7,99^{*} \\
(2,82)\end{array}$ & $\begin{array}{c}8,32 \\
(2,92)\end{array}$ & $\begin{array}{l}7,60 \\
(2,76)\end{array}$ \\
\hline Estudo -11 a 13 & $\begin{array}{l}8,34 \\
(2,86)\end{array}$ & $\begin{array}{l}7,09 \\
(2,52)\end{array}$ & $\begin{array}{c}8,38 \\
(3,18)\end{array}$ & $\begin{array}{l}8,31^{*} \\
(2,89)\end{array}$ & $\begin{array}{c}8,65 \\
(3,08)\end{array}$ & $\begin{array}{l}7,96 \\
(2,96)\end{array}$ \\
\hline Estudo - mais de 13 & $\begin{array}{l}16,08 \\
(7,10)\end{array}$ & $\begin{array}{l}14,54 \\
(6,10)\end{array}$ & $\begin{array}{l}16,94 \\
(7,27)\end{array}$ & $\begin{array}{l}15,79 \\
(6,77)\end{array}$ & $\begin{array}{l}18,72 \\
(8,15)\end{array}$ & $\begin{array}{l}16,38 \\
(7,15)\end{array}$ \\
\hline $\operatorname{Rural}^{b}$ & $\begin{array}{c}6,12 \\
(1,63)\end{array}$ & $\begin{array}{r}4,80 \\
(1,26)\end{array}$ & $\begin{array}{l}6,47 \\
(2,29)\end{array}$ & $\begin{array}{l}6,24 \\
(1,93)\end{array}$ & $\begin{array}{l}7,48 \\
(3,03)\end{array}$ & $\begin{array}{l}5,91 \\
(2,13)\end{array}$ \\
\hline Urbana & $\begin{array}{l}8,34 \\
(3,44)\end{array}$ & $\begin{array}{c}6,90 \\
(3,08)\end{array}$ & $\begin{array}{c}8,70 \\
(4,23)\end{array}$ & $\begin{array}{l}8,60 \\
(3,96)\end{array}$ & $\begin{array}{c}8,74 \\
(4,33)\end{array}$ & $\begin{array}{l}8,05 \\
(3,86)\end{array}$ \\
\hline Não metrópole ${ }^{b}$ & $\begin{array}{l}7,33 \\
(2,54)\end{array}$ & $\begin{array}{l}5,83 \\
(2,26)\end{array}$ & $\begin{array}{l}7,45 \\
(2,97)\end{array}$ & $\begin{array}{l}7,39 \\
(2,83)\end{array}$ & $\begin{array}{c}7,73 \\
(3,19)\end{array}$ & $\begin{array}{l}6,99 \\
(2,84)\end{array}$ \\
\hline Metrópole & $\begin{array}{c}9,58 \\
(4,11)\end{array}$ & $\begin{array}{l}7,46 \\
(3,33)\end{array}$ & $\begin{array}{c}9,54 \\
(4,76)\end{array}$ & $\begin{array}{c}9,38 \\
(4,43)\end{array}$ & $\begin{array}{r}10,35 \\
(5,33)\end{array}$ & $\begin{array}{l}8,80 \\
(4,36)\end{array}$ \\
\hline Não migrante ${ }^{b}$ & $\begin{array}{l}7,97 \\
(3,05)\end{array}$ & $\begin{array}{l}6,69 \\
(2,91)\end{array}$ & $\begin{array}{c}8,41 \\
(4,10)\end{array}$ & $\begin{array}{c}8,29 \\
(3,73)\end{array}$ & $\begin{array}{c}7,93 \\
(3,08)\end{array}$ & $\begin{array}{l}7,68 \\
(3,55)\end{array}$ \\
\hline Migrante & $\begin{array}{c}9,01 \\
(4,60)\end{array}$ & $\begin{array}{c}8,01 \\
(4,28)\end{array}$ & $\begin{array}{c}9,63 \\
(4,50)\end{array}$ & $\begin{array}{r}10,13 \\
(5,05)\end{array}$ & $\begin{array}{c}9,88 \\
(5,50)\end{array}$ & $\begin{array}{c}9,40 \\
(4,87)\end{array}$ \\
\hline
\end{tabular}

Fonte: Elaboração própria a partir dos dados da PNAD de 2006. Os valores entre parênteses correspondem ao desvio padrão. b Categoria de referência no teste $t$-student para diferença de médias. ${ }^{*}$ Diferença de média em relação à categoria base não é estatisticamente significativa a 5\%. 
(2007), que trata, exclusivamente, das pessoas economicamente não ativas, e de Mohanty (2005), que considera trabalhadores ocupados, desocupados e inativos.

A Tabela 6, a seguir, mostra o resultado das estimações do salário de reserva para os inativos, obtidas a partir da 10 , e segundo as características pessoais e por regiões.

Tabela 6: Brasil: salário-hora de reserva médio para indivíduos inativos, segundo características individuais e por regiões -2006 (em R\$)

\begin{tabular}{|c|c|c|c|c|c|c|}
\hline & Norte & Nordeste & Sudeste & Sul & Centro-Oeste & Total \\
\hline Mulher ${ }^{b}$ & $\begin{array}{l}17,03 \\
(08,67)\end{array}$ & $\begin{array}{l}14,50 \\
(08,16)\end{array}$ & $\begin{array}{l}20,78 \\
(11,42)\end{array}$ & $\begin{array}{c}21,01 \\
(11,05)\end{array}$ & $\begin{array}{l}20,52 \\
(12,01)\end{array}$ & $\begin{array}{l}18,30 \\
(10,55)\end{array}$ \\
\hline Homem & $\begin{array}{l}12,75 \\
(06,52)\end{array}$ & $\begin{array}{l}10,44 \\
(05,30)\end{array}$ & $\begin{array}{l}14,36 \\
(06,96)\end{array}$ & $\begin{array}{l}14,31 \\
(06,62)\end{array}$ & $\begin{array}{l}14,69 \\
(08,07)\end{array}$ & $\begin{array}{l}12,93 \\
(06,74)\end{array}$ \\
\hline Não branco ${ }^{b}$ & $\begin{array}{l}14,54 \\
(06,98)\end{array}$ & $\begin{array}{l}11,98 \\
(05,94)\end{array}$ & $\begin{array}{l}15,17 \\
(07,32)\end{array}$ & $\begin{array}{l}14,12 \\
(07,11)\end{array}$ & $\begin{array}{l}16,00 \\
(08,23)\end{array}$ & $\begin{array}{l}13,78 \\
(07,00)\end{array}$ \\
\hline Branco & $\begin{array}{c}20,03 \\
(10,52)\end{array}$ & $\begin{array}{l}16,68 \\
(09,94)\end{array}$ & $\begin{array}{c}21,74 \\
(11,93)\end{array}$ & $\begin{array}{c}20,43 \\
(10,79)\end{array}$ & $\begin{array}{l}23,03 \\
(13,55)\end{array}$ & $\begin{array}{l}20,39 \\
(11,55)\end{array}$ \\
\hline Não chefe ${ }^{b}$ & $\begin{array}{l}15,78 \\
(08,33)\end{array}$ & $\begin{array}{l}13,28 \\
(07,82)\end{array}$ & $\begin{array}{l}19,22 \\
(11,31)\end{array}$ & $\begin{array}{l}19,39 \\
(10,97)\end{array}$ & $\begin{array}{l}18,91 \\
(11,68)\end{array}$ & $\begin{array}{l}16,79 \\
(10,25)\end{array}$ \\
\hline Chefe de família & $\begin{array}{l}16,94 \\
(08,67)\end{array}$ & $\begin{array}{l}14,18 \\
(07,22)\end{array}$ & $\begin{array}{c}18,51 \\
(08,85)\end{array}$ & $\begin{array}{l}18,79 \\
(08,84)\end{array}$ & $\begin{array}{l}20,10 \\
(10,49)\end{array}$ & $\begin{array}{l}17,36 \\
(08,85)\end{array}$ \\
\hline Idade - 16 a $20^{b}$ & $\begin{array}{l}12,76 \\
(03,03)\end{array}$ & $\begin{array}{l}10,16 \\
(02,46)\end{array}$ & $\begin{array}{l}12,39 \\
(02,83)\end{array}$ & $\begin{array}{l}12,65 \\
(02,78)\end{array}$ & $\begin{array}{l}13,36 \\
(03,20)\end{array}$ & $\begin{array}{l}11,79 \\
(03,04)\end{array}$ \\
\hline Idade - 21 a 24 & $\begin{array}{l}11,42 \\
(03,59)\end{array}$ & $\begin{array}{r}9,03 \\
(02,97)\end{array}$ & $\begin{array}{l}12,10 \\
(04,58)\end{array}$ & $\begin{array}{l}12,52^{*} \\
(04,93)\end{array}$ & $\begin{array}{l}12,85 \\
(05,01)\end{array}$ & $\begin{array}{l}10,96 \\
(04,27)\end{array}$ \\
\hline Idade - 25 a 30 & $\begin{array}{l}11,75 \\
(03,46)\end{array}$ & $\begin{array}{r}9,31 \\
(03,11)\end{array}$ & $\begin{array}{l}12,05 \\
(04,49)\end{array}$ & $\begin{array}{l}12,43^{*} \\
(04,67)\end{array}$ & $\begin{array}{l}12,52 \\
(04,61)\end{array}$ & $\begin{array}{l}11,11 \\
(04,14)\end{array}$ \\
\hline Idade - 31 a 40 & $\begin{array}{l}14,05 \\
(04,75)\end{array}$ & $\begin{array}{l}10,94 \\
(03,68)\end{array}$ & $\begin{array}{l}13,99 \\
(05,02)\end{array}$ & $\begin{array}{l}14,19 \\
(04,91)\end{array}$ & $\begin{array}{l}14,84 \\
(05,54)\end{array}$ & $\begin{array}{l}13,14 \\
(04,90)\end{array}$ \\
\hline Idade - 41 a 65 & $\begin{array}{l}26,48 \\
(10,00)\end{array}$ & $\begin{array}{l}21,56 \\
(09,14)\end{array}$ & $\begin{array}{l}26,17 \\
(11,50)\end{array}$ & $\begin{array}{l}26,07 \\
(11,05)\end{array}$ & $\begin{array}{l}29,00 \\
(13,15)\end{array}$ & $\begin{array}{l}25,32 \\
(11,19)\end{array}$ \\
\hline Estudo - 1 a $3^{b}$ & $\begin{array}{l}15,94 \\
(07,22)\end{array}$ & $\begin{array}{l}12,41 \\
(05,84)\end{array}$ & $\begin{array}{l}17,55 \\
(06,89)\end{array}$ & $\begin{array}{l}18,33 \\
(06,72)\end{array}$ & $\begin{array}{l}18,83 \\
(07,66)\end{array}$ & $\begin{array}{l}15,70 \\
(07,13)\end{array}$ \\
\hline Estudo - 4 a 7 & $\begin{array}{l}14,51 \\
(06,79)\end{array}$ & $\begin{array}{l}11,97 \\
(05,69)\end{array}$ & $\begin{array}{l}17,39^{*} \\
(07,72)\end{array}$ & $\begin{array}{l}17,70 \\
(07,41)\end{array}$ & $\begin{array}{l}16,69 \\
(07,88)\end{array}$ & $\begin{array}{l}15,18 \\
(07,38)\end{array}$ \\
\hline Estudo - 8 a 10 & $\begin{array}{l}14,44 \\
(05,70)\end{array}$ & $\begin{array}{l}12,21^{*} \\
(05,28)\end{array}$ & $\begin{array}{l}15,88 \\
(07,29)\end{array}$ & $\begin{array}{l}15,94 \\
(07,02)\end{array}$ & $\begin{array}{l}15,96 \\
(07,09)\end{array}$ & $\begin{array}{l}14,55 \\
(06,64)\end{array}$ \\
\hline Estudo -11 a 13 & $\begin{array}{l}16,97 \\
(07,78)\end{array}$ & $\begin{array}{l}14,55 \\
(06,60)\end{array}$ & $\begin{array}{l}18,90 \\
(08,28)\end{array}$ & $\begin{array}{l}18,61^{*} \\
(08,17)\end{array}$ & $\begin{array}{l}19,24^{*} \\
(08,92)\end{array}$ & $\begin{array}{l}17,36 \\
(08,05)\end{array}$ \\
\hline Estudo -mais de 13 & $\begin{array}{l}39,11 \\
(16,94)\end{array}$ & $\begin{array}{l}36,01 \\
(16,08)\end{array}$ & $\begin{array}{l}43,27 \\
(17,73)\end{array}$ & $\begin{array}{l}41,27 \\
(17,01)\end{array}$ & $\begin{array}{l}44,87 \\
(20,80)\end{array}$ & $\begin{array}{l}41,28 \\
(17,91)\end{array}$ \\
\hline Rural $^{b}$ & $\begin{array}{l}12,23 \\
(05,01)\end{array}$ & $\begin{array}{r}9,29 \\
(03,71)\end{array}$ & $\begin{array}{l}13,08 \\
(06,06)\end{array}$ & $\begin{array}{l}14,67 \\
(06,57)\end{array}$ & $\begin{array}{l}14,31 \\
(07,44)\end{array}$ & $\begin{array}{l}11,47 \\
(05,57)\end{array}$ \\
\hline Urbana & $\begin{array}{l}16,54 \\
(08,66)\end{array}$ & $\begin{array}{l}14,19 \\
(08,02)\end{array}$ & $\begin{array}{l}19,43 \\
(10,92)\end{array}$ & $\begin{array}{l}19,62 \\
(10,67)\end{array}$ & $\begin{array}{l}19,62 \\
(11,69)\end{array}$ & $\begin{array}{l}17,54 \\
(10,20)\end{array}$ \\
\hline Não metrópole ${ }^{b}$ & $\begin{array}{l}14,73 \\
(07,30)\end{array}$ & $\begin{array}{l}11,49 \\
(05,97)\end{array}$ & $\begin{array}{l}16,81 \\
(08,94)\end{array}$ & $\begin{array}{l}17,24 \\
(08,86)\end{array}$ & $\begin{array}{l}17,47 \\
(09,36)\end{array}$ & $\begin{array}{l}14,99 \\
(08,30)\end{array}$ \\
\hline Metrópole & $\begin{array}{l}19,07 \\
(10,02)\end{array}$ & $\begin{array}{l}15,95 \\
(08,91)\end{array}$ & $\begin{array}{l}21,55 \\
(12,06)\end{array}$ & $\begin{array}{l}21,34 \\
(11,60)\end{array}$ & $\begin{array}{l}23,31 \\
(14,77)\end{array}$ & $\begin{array}{l}19,58 \\
(11,42)\end{array}$ \\
\hline Não migrante $b$ & $\begin{array}{l}15,15 \\
(07,87)\end{array}$ & $\begin{array}{l}13,11 \\
(07,36)\end{array}$ & $\begin{array}{l}18,34 \\
(10,49)\end{array}$ & $\begin{array}{l}18,71 \\
(10,14)\end{array}$ & $\begin{array}{l}15,78 \\
(07,54)\end{array}$ & $\begin{array}{l}15,96 \\
(09,22)\end{array}$ \\
\hline Migrante & $\begin{array}{l}18,73 \\
(09,46)\end{array}$ & $\begin{array}{l}16,86 \\
(10,24)\end{array}$ & $\begin{array}{l}21,99 \\
(11,51)\end{array}$ & $\begin{array}{l}22,94 \\
(12,10)\end{array}$ & $\begin{array}{l}23,17 \\
(13,84)\end{array}$ & $\begin{array}{l}21,09 \\
(11,99)\end{array}$ \\
\hline
\end{tabular}

Fonte: Elaboração própria a partir dos dados da PNAD de 2006. Os valores entre parênteses correspondem ao desvio padrão. b Categoria de referência no teste $t$-student para diferença de médias. * Diferença de média em relação à categoria base não é estatisticamente significativa a $5 \%$. 
Os resultados preservam as mesmas características dos anteriores, uma vez que se verifica, em geral, maior salário-hora de reserva para as mulheres, brancos, migrantes, pessoas mais experientes, pessoas mais instruídas, moradores de áreas urbanas ou de metrópoles. Por outro lado, percebe-se que o valor médio do salário de reserva é bem maior que os estimados para os trabalhadores ocupados e desocupados, considerando todas as faixas de idade e de instrução, por exemplo. Tal fato é consistente com a condição de atividade dessas pessoas, que conforme já observado, possui, em geral, de 41 e 65 anos de idade, faixa etária onde é maior a presença de rendimentos provenientes do não trabalho (aposentadoria e pensões). Estes resultados estão consistentes com a explicação da teoria da oferta de trabalho, visto que os trabalhadores permanecem fora da força de trabalho quando os seus salários de reserva são maiores do que os seus salários de mercado esperados (Mohanty 2005).

Uma outra peculiaridade refere-se à diferenciação do salário de reserva segundo a condição familiar. Ao contrário dos resultados obtidos para os trabalhadores ocupados e desempregados, o salário de reserva do inativo chefe de família chega a superar, embora em pequeno valor, aquele verificado para o inativo não responsável pelo domicílio, tanto nacionalmente, quanto nas regiões Norte e Centro-Oeste. A justificativa para este resultado pode estar no fato de que a não participação dos indivíduos, em geral, dos adultos, depende de outros fatores não salariais (Blau 1991, Mohanty 2005). Blackaby (2007), por exemplo, ressaltam que os indivíduos economicamente inativos e, particularmente, aqueles que indicam algum desejo de trabalhar, seriam influenciados a procurar emprego caso ocorressem mudanças nos benefícios concedidos pelo Governo aos mesmos.

\section{Considerações finais}

Este artigo teve como objetivo principal a estimação do salário de reserva para os indivíduos ocupados, desocupados e inativos no Brasil. Em termos específicos, buscou-se descrever o perfil desses indivíduos e observar a relação de determinação existente entre suas características socioeconômicas e o salário de reserva estimado.

A análise estatística da amostra revelou que as principais diferenças entre o trabalhador ocupado, desocupado e inativo são devidas ao gênero, à posição familiar, à faixa etária e ao nível de instrução. Enquanto o trabalhador ocupado é homem, chefe de família, bastante experiente (de 41 a 65 anos de idade) e escolarizado (de 10 a 13 anos de estudo), o desocupado é mulher, não responsável pela família, jovem (de 16 a 20 anos de idade) e com nível intermediário de instrução (de 4 a 10 anos de estudo). Já o trabalhador inativo é mulher, não responsável pelo domicílio, bastante experiente (de 41 a 65 anos) e com baixo nível de instrução (de 4 a 7 anos de estudo).

Os resultados empíricos, especialmente relacionados aos determinantes conjuntos da oferta de trabalho, emprego e salários, foram bastante consistentes com abordagem das teorias do Capital Humano e da Procura por Emprego. Nesse sentido, foram encontradas evidências que correlacionam diretamente o ingresso no mercado de trabalho, a empregabilidade e as remunerações ao investimento em educação e à experiência. Já no tocante às estimativas acerca dos salários de reserva para trabalhadores ocupados, desocupados e inativos, as evidências foram bastante sugestivas. 
Primeiro, verificou-se que as mulheres, as pessoas de cor branca e os migrantes registram maiores salários de reserva quando comparadas aos homens, não brancos e não migrantes, respectivamente. Os moradores de zonas urbanas e/ou metrópoles também revelaram salários de reserva superiores aos residentes em áreas rurais ou em pequenas e médias cidades. Tais evidências chamaram atenção para os potenciais impactos das diferenças de custo de vida, custo de migração e discriminação por gênero e raça, sobre as preferências das pessoas no que tange ao ingresso no mercado de trabalho.

Segundo, as diferenças de salário de reserva por faixa etária e de instrução, apenas alcançam patamares expressivos quando o trabalhador é muito experiente e/ou instruído, fato que, no Brasil, pode se correlacionar com a escassez por mão de obra qualificada e/ou com o alto retorno para o investimento em capital humano.

Por fim, foi constatado que o salário de reserva do indivíduo inativo é bastante superior aos estimados para trabalhadores ocupados e desempregados, característica que se mostrou consistente com maior faixa etária dos inativos e com a presença de rendimentos do não trabalho. De maneira geral, os principais aspectos abordados apontam conformidade com o arcabouço teórico utilizado, embora alguns elementos desta não consigam explicar efetivamente a realidade do mercado de trabalho brasileiro. Todavia, reconhece-se a importância de estudar os determinantes do salário de reserva e sua mensuração, visto que o salário de reserva tem relação direta com as questões relacionadas ao próprio funcionamento do mercado de trabalho, sendo útil, até mesmo, para um possível direcionamento das políticas de geração de emprego e renda. 


\section{Referências Bibliográficas}

Barros, R., Ramos, L. \& Santos, E. (1995), Gender differences in brazilian labor markets., in P. Schultz., ed., 'Investment in women's human capital', University of Chicago Press.

Becker, G. S. (1962), 'Investiment in human capital: A theoretical analysis.', Journal of Political Economy 70, 9-49.

Blackaby, D. H. (2007), 'An analysis of reservation wages for the economically inactive.', Economic Letters. 97, 1-5.

Blau, D. M. (1991), 'Search for nonwage job characteristics: a test of the reservation wage hypothesis.', Journal of Labor Economics 9, 186-205.

Bloemen, H. (1997), 'Job search theory, labour supply and unemployment duration.', Journal of Econometrics. 79(2), 305-325.

Cahuc, P. \& Zylberberg, A. (2004), 'Labor economics.', Cambridge: MIT Press.

Fitzgerald, T. J. (1998), 'An introduction to the search theory of unemployment.', International Economic Review. 34, 2-15.

Gobillon, L. \& Le Blanc, D. (2003), 'Migrations, incomes and unobserved heterogeneity.', Working Paper No. 2003-47 pp. 1-32.

Heckman, J. J. (1979), 'Sample selection bias as a specification error', Econometrica $47,153-161$.

Heckman, J. J. (1990), 'Varieties of selection bias.', The American Economic Review 80, 313-318.

Hinnosaar, M. (2004), 'Unemployment, reservation wage, and job search.', The Journal Kroon \& Economy pp. 32-39.

Hofler, R. \& Murphy, K. (1994), 'Estimating reservation wages of employed workers using a stochastic frontier.', Southern Economic Journal 60, 961-976.

Jones, S. (1988), 'The relationship between unemployment spells and reservation wages as a test of search theory.', Quarterly Journal of Economics 103, 741-765.

Kassouf, A. L. \& Silva, N. (2002), 'A exclusão social dos jovens no mercado de trabalho brasileiro.', Revista Brasileira de Estudos de População, 19, 99-115.

Kiefer, N. M. \& Neumann, G. R. (1979), 'An empirical job-search model, with a test of the constant reservation-wage hypothesis.', The Journal of Political Economy 87, 89-107.

Lee, L.-F. (1978), 'Unionism and wage rates: A simultaneous equations model with qualitative and limited dependent variables.', International Economic Review 19, 415-433.

McCall, J. J. (1970), 'Economics of information and job search.', Quarterly Journal of Economics. 84, 113-126. 
Mendonça, R. P. B. \& R. (1995), Bem-estar, pobreza e desigualdade de renda:uma avaliação da evolução histórica e das disparidades regionais, Textos para discussão, IPEA.

Menezes, A. W. F., Carrera-Fernandez, J. \& Dedecca, C. S. (2005), 'Diferenciações regionais de rendimentos do trabalho: uma análise das regiões metropolitanas de são paulo e salvador.', Estudos Econômicos 35, 271-296.

Menezes Filho, N. A. \& Jr., R. M. (2003), 'Tecnologia e demanda por qualificação na indústria brasileira', Revista Brasileira de Economia 57(3), 569-603.

Mincer, J. (1958), 'Investment in human capital and personal income distribution.', The Journal of Political Economy 66, 281-302.

Mohanty, M. S. (2005), 'An alternative method of estimating the worker's reservation wages.', International Economic Journal. 19, 501-522.

Mortensen, D. T. (1970), 'Job search, the duration of unemployment, and the phillips curve.', American Economic Review 60, 847-862.

Oliveira, V. \& Carvalho, J. (2006), 'Salário de reserva e duração do desemprego no brasil: uma análise com dados da pesquisa de padrão de vida do ibge.', Encontro Regional de Economia. .

Pannenberg, M. (2007), 'Risk aversion and reservation wages.', IZA Discussion Papers 2806, Institute for the Study of Labor (IZA).

Peralta, J. D. (2005), Determinantes del salario de reserva en el mercado laboral de cali en el ano 2004/2005., Technical report, Documentos De Trabajo 004112, Universidad Del Valle - CIDSE.

Ricardo, D. (2006), Princípios de Economia Política e Tributação., São Paulo: Nova Cultural.

Rogerson, R., Shimer, R. \& Wright, R. (2005), 'Search-theoretic models of the labor market: A survey', Journal of Economic Perspectives 959-988.

Rõõm, M. (2003), Reservation wages in estonia. labor and demography 0303001, Technical report, EconWPA.

Santos Junior, E. R., Menezes Filho, N. A. \& Ferreira, P. C. (2005), 'Migração, seleção e diferenças regionais de renda no brasil.', Pesquisa e Planejamento Econômico 35, 299-332.

Schultz, T. (1961), 'Investment in human capital.', The American Economic Review 51, 1-17.

Smith, A. (1996), A Riqueza das Nações: Investigação Sobre sua Natureza e suas Causas., São Paulo: Nova Cultural.

Tunali, I. (1986), 'A general structure for models of double selection and an application to a joint migration/earning process with remigration.', Research in Labor Economics 8, 235-282.

Whipple, D. (1973), 'A generalized theory of job search.', Journal of Political Economy 81, 1170-1188. 


\section{Apêndice A}

Tabela A.1: Descrição das variáveis utilizadas nas regressões

\begin{tabular}{|c|c|c|}
\hline Variável & Definição & Variável de origem \\
\hline Ativo & $\begin{array}{l}1 \text { - se o indivíduo é economicamente ativo e } 0 \\
\text { se inativo* }\end{array}$ & V4704 \\
\hline Ocupado & $\begin{array}{l}1 \text { - se o indivíduo se achava empregado e } 0 \text { se } \\
\text { economicamente ativo ou inativo* }\end{array}$ & V4705 \\
\hline Log salário-hora & $\begin{array}{l}\text { Logaritmo do salário do trabalho principal por } \\
\text { horas de trabalho semanais }\end{array}$ & V4718 \\
\hline Homem & $\begin{array}{l}1 \text { - se o indivíduo é sexo masculino e } 0 \text { - se sexo } \\
\text { feminino* }\end{array}$ & V0302 \\
\hline Branco & $\begin{array}{l}1 \text { - se o indivíduo é cor branca e } 0 \text { - caso } \\
\text { contrário* }^{*}\end{array}$ & V0404 \\
\hline Idade & Idade do indivíduo em anos & V8005 \\
\hline Idade ao Quadrado & $\begin{array}{l}\text { Idade do indivíduo em anos elevada ao } \\
\text { quadrado }\end{array}$ & V8005 \\
\hline Idade - 21 a 24 & $\begin{array}{l}1 \text { - se a faixa etária corresponde ao intervalo de } \\
21 \text { a } 24 \text { anos e } 0 \text { - faixa etária de } 16 \text { a } 20 \text { anos }^{*}\end{array}$ & V8005 \\
\hline Idade - 25 a 30 & $\begin{array}{l}1 \text { - se a faixa etária corresponde ao intervalo de } \\
25 \text { a } 30 \text { anos e } 0 \text { - faixa etária de } 16 \text { a } 20 \text { anos }^{*}\end{array}$ & V8005 \\
\hline Idade - 31 a 40 & $\begin{array}{l}1 \text { - se a faixa etária corresponde ao intervalo de } \\
31 \text { a } 40 \text { anos e } 0 \text { - faixa etária de } 16 \text { a } 20 \text { anos }^{*}\end{array}$ & V8005 \\
\hline Idade - 41 a 65 & $\begin{array}{l}1 \text { - se a faixa etária corresponde ao intervalo de } \\
41 \text { a } 65 \text { anos e } 0 \text { - faixa etária de } 16 \text { a } 20 \text { anos }^{*}\end{array}$ & V8005 \\
\hline Estudo - 4 a 7 & $\begin{array}{l}1 \text { - se a faixa de escolaridade corresponde ao } \\
\text { intervalo de } 4 \text { a } 7 \text { anos de estudo e } 0 \text { - de } 1 \text { a } 3 \\
\text { anos }\end{array}$ & V4703 \\
\hline Estudo - 8 a 10 & $\begin{array}{l}1 \text { - se a faixa de escolaridade corresponde ao } \\
\text { intervalo de } 8 \text { a } 10 \text { anos de estudo e } 0 \text { - de } 1 \text { a } 3 \\
\text { anos }^{*}\end{array}$ & V4703 \\
\hline Estudo - 11 a 13 & $\begin{array}{l}1 \text { - se a faixa de escolaridade corresponde ao } \\
\text { intervalo de } 11 \text { a } 13 \text { anos de estudo e } 0 \text { - de } 1 \text { a } \\
3 \text { anos }^{*}\end{array}$ & V4703 \\
\hline Estudo - mais de 13 & $\begin{array}{l}1 \text { - se a faixa de escolaridade corresponde a } \\
\text { mais de } 13 \text { anos de estudo e } 0 \text { - de } 1 \text { a } 3 \text { anos }^{*}\end{array}$ & V4703 \\
\hline Chefe & $\begin{array}{l}1 \text { - se o indivíduo é responsável pelo domicílio } \\
\text { e } 0 \text { - caso contrário* }\end{array}$ & V0401 \\
\hline Moradores & Número de moradores no domicílio & V4741 \\
\hline Urbana & $\begin{array}{l}1 \text { - se o indivíduo reside em zona urbana e } 0 \text { - } \\
\text { em zona rural }{ }^{*}\end{array}$ & V4728 \\
\hline Metrópole & $\begin{array}{l}1 \text { - se o indivíduo reside em área metropolitana } \\
\text { e } 0 \text { - caso contrário }{ }^{*}\end{array}$ & V4727 \\
\hline Norte & $\begin{array}{l}1 \text { - se a pessoa reside na região Norte e } 0 \text { - se } \\
\text { reside na região Sudeste* }\end{array}$ & UF \\
\hline Nordeste & $\begin{array}{l}1 \text { - se a pessoa reside na região Nordeste e } 0 \text { - se } \\
\text { reside na região Sudeste }\end{array}$ & UF \\
\hline Sul & $\begin{array}{l}1 \text { - se a pessoa reside na região Sul e } 0 \text { - se } \\
\text { reside na região Sudeste* }\end{array}$ & UF \\
\hline Centro-Oeste & $\begin{array}{l}1 \text { - se a pessoa reside na região Centro-Oeste e } 0 \\
\text { - se reside na região Sudeste* }\end{array}$ & UF \\
\hline
\end{tabular}

Fonte: Elaboração própria a partir dos dados da PNAD de 2006. Nota: ${ }^{\star}$ Categoria omitida. 
Tabela A.2: Estatísticas descritivas da amostra

\begin{tabular}{|c|c|c|c|c|c|c|}
\hline & \multicolumn{2}{|c|}{ Ocupados } & \multicolumn{2}{|c|}{ Desocupados } & \multicolumn{2}{|c|}{ Inativos } \\
\hline & Média & $\begin{array}{l}\text { Desvio } \\
\text { padrão }\end{array}$ & Média & $\begin{array}{l}\text { Desvio } \\
\text { padrão }\end{array}$ & Média & $\begin{array}{l}\text { Desvio } \\
\text { padrão }\end{array}$ \\
\hline Homem $^{*}$ & 0,55 & 0,50 & 0,42 & 0,49 & 0,26 & 0,44 \\
\hline Branco $^{*}$ & 0,48 & 0,50 & 0,41 & 0,49 & 0,47 & 0,50 \\
\hline Idade & 33,74 & 11,23 & 27,91 & 10,49 & 35,20 & 15,83 \\
\hline Idade ao Quadrado & $1.264,66$ & 830,92 & 889,02 & 721,51 & $1.490,01$ & $1.226,37$ \\
\hline Idade -21 a $24^{*}$ & 0,14 & 0,35 & 0,20 & 0,40 & 0,11 & 0,31 \\
\hline Idade - 25 a $30^{*}$ & 0,20 & 0,40 & 0,19 & 0,39 & 0,11 & 0,31 \\
\hline Idade -31 a $40^{*}$ & 0,27 & 0,44 & 0,17 & 0,38 & 0,14 & 0,35 \\
\hline Idade - 41 a $65^{*}$ & 0,28 & 0,45 & 0,14 & 0,35 & 0,38 & 0,48 \\
\hline Estudo - 4 a $7^{\star}$ & 0,24 & 0,43 & 0,25 & 0,43 & 0,33 & 0,47 \\
\hline Estudo - 8 a $10^{*}$ & 0,19 & 0,39 & 0,28 & 0,45 & 0,26 & 0,44 \\
\hline Estudo -11 a $13^{*}$ & 0,36 & 0,48 & 0,36 & 0,48 & 0,23 & 0,42 \\
\hline Estudo - mais $13^{*}$ & 0,13 & 0,34 & 0,05 & 0,22 & 0,05 & 0,22 \\
\hline Chefe ${ }^{*}$ & 0,43 & 0,49 & 0,19 & 0,39 & 0,20 & 0,40 \\
\hline Moradores & 3,96 & 1,81 & 4,42 & 1,97 & 4,24 & 1,92 \\
\hline Urbana $^{*}$ & 0,91 & 0,29 & 0,95 & 0,23 & 0,89 & 0,31 \\
\hline Metrópole ${ }^{*}$ & 0,42 & 0,49 & 0,52 & 0,50 & 0,42 & 0,49 \\
\hline Migrante $^{*}$ & 0,19 & 0,39 & 0,15 & 0,35 & 0,18 & 0,39 \\
\hline Norte $^{*}$ & 0,11 & 0,32 & 0,11 & 0,31 & 0,14 & 0,34 \\
\hline Nordeste $^{*}$ & 0,26 & 0,44 & 0,34 & 0,47 & 0,31 & 0,46 \\
\hline $\mathrm{Sul}^{*}$ & 0,17 & 0,38 & 0,12 & 0,32 & 0,14 & 0,35 \\
\hline Centro-Oeste $^{*}$ & 0,12 & 0,33 & 0,11 & 0,31 & 0,11 & 0,31 \\
\hline Observações & \multicolumn{2}{|c|}{111.382} & \multicolumn{2}{|c|}{16.775} & \multicolumn{2}{|c|}{59.999} \\
\hline
\end{tabular}

Fonte: Elaboração própria a partir dos dados da PNAD de 2006. Nota: * Variável categórica média equivale à proporção em relação à categoria de referência. 